\title{
Effect of dried oregano (Origanum vulgare L.) plant material in feed on methane production, rumen fermentation, nutrient digestibility, and milk fatty acid composition in dairy cows
}

\author{
D. W. Olijhoek, ${ }^{1,2 *}$ A. L. F. Hellwing, ${ }^{1}$ K. Grevsen, ${ }^{3}$ L. S. Haveman, ${ }^{1}$ M. R. Chowdhury, ${ }^{1}$ P. Løvendahl, ${ }^{2}$ \\ M. R. Weisbjerg, ${ }^{1}$ S. J. Noel, ${ }^{1}$ O. Højberg, ${ }^{1}$ L. Wiking, ${ }^{4}$ and P. Lund ${ }^{1}$ \\ ${ }^{1}$ Department of Animal Science, AU Foulum, Aarhus University, DK 8830 Tjele, Denmark \\ ${ }^{2}$ Department of Molecular Biology and Genetics, AU Foulum, Aarhus University, DK 8830 Tjele, Denmark \\ ${ }^{3}$ Department of Food Science, AU Aarslev, Aarhus University, DK 5792 Aarslev, Denmark \\ ${ }^{4}$ Department of Food Science, AU Foulum, Aarhus University, DK 8830 Tjele, Denmark
}

\section{ABSTRACT}

Essential oils (EO) from oregano may have antimicrobial properties, potentially representing a methane mitigation strategy suitable for organic production. This study aimed to (1) examine the potential of oregano in lowering enteric methane production of dairy cows fed differing levels of dried oregano (Origanum vulgare ssp. hirtum) plant material containing high levels of EO; (2) determine whether differing levels of dried oregano plant material of another subspecies (Origanum vulgare ssp. vulgare) with naturally low levels of EO in feed affected enteric methane production; and (3) evaluate the effect of various levels of the 2 oregano subspecies (containing high or low levels of EO) in feed on rumen fermentation, nutrient digestibility, and milk fatty acids. Each experiment had a $4 \times 4$ Latin square design using 4 lactating Danish Holstein dairy cows that had rumen, duodenal, and ileal cannulas and were fed 4 different levels of oregano. Experiment 1 used low EO oregano $[0.12 \%$ EO of oregano dry matter (DM)] and evaluated a control (C) diet with no oregano and 3 oregano diets with 18 (low; L), 36 (medium; M), and $53 \mathrm{~g}$ of oregano $\mathrm{DM} / \mathrm{kg}$ of dietary DM (high; H). Experiment 2 used high EO oregano (4.21\% EO of oregano DM) with 0, 7 , 14 , and $21 \mathrm{~g}$ of oregano $\mathrm{DM} / \mathrm{kg}$ of dietary $\mathrm{DM}$ for $\mathrm{C}$, $\mathrm{L}, \mathrm{M}$, and $\mathrm{H}$, respectively. Oregano was added to the diets by substituting grass/clover silage on a DM basis. Low or high EO oregano in feed did not affect dry matter intake (DMI) or methane production (grams per day, grams per kilogram of DMI, grams per kilogram of energy-corrected milk, and percentage of gross energy intake). Rumen fermentation was slightly affected by diet in experiment 1 , but was not affected by diet in experiment 2 . In both experiments, the apparent total-

Received January 18, 2019.

Accepted July 11, 2019

*Corresponding author: Dana.Olijhoek@anis.au.dk tract digestibility of DM, organic matter, and neutral detergent fiber decreased linearly and cubically (a cubic response was not observed for neutral detergent fiber) with increasing dietary oregano content, while milk fatty acids were slightly affected. In conclusion, dried oregano plant material with either high or low levels of EO did not lower the methane production of dairy cows over 4 consecutive days, and no substantial effects were observed on rumen fermentation or nutrient digestibility. This conclusion regarding methane production is in contrast with literature and requires further study.

Key words: oregano, essential oil, methane, dairy cow, rumen fermentation

\section{INTRODUCTION}

The emission of enteric methane, especially from dairy production, constitutes a significant part of the contribution of agriculture to global warming, accounting for $17 \%$ of global methane emissions (Knapp et al., 2014). Consequently, the potential of plant-based feed additives, such as essential oils (EO), is being investigated because they could represent a suitable methane mitigation strategy for ruminants. Plant-based feed additives are of particular interest for organic animal production because feed additives of natural origin fit better with the organic mindset than feed additives of synthetic origin. Essential oils are derived from herbs or medicinal plants (Benchaar and Greathead, 2011), including oregano (Origanum vulgare), garlic (Allium sativum), or horseradish (Armoracia rusticana). Essential oils are volatile plant secondary metabolites that give plants their characteristic odor and flavor. They protect plants from damage by microorganisms, herbivores, and UV-B radiation (Bosabalidis, 2002). Essential oils have strong and nonspecific antimicrobial properties; however, microbes exhibit differing levels of sensitivity to EO (Benchaar and Greathead, 2011). Thus, EO could potentially alter rumen microbial 
metabolism (fermentation and methanogenesis) by directly reducing the abundance of rumen archaea or by inhibiting fibrolytic bacteria that provide a substrate (e.g., hydrogen) for methanogenic archaea (Cobellis et al., 2016b). However, a decline in the digestibility of nutrients, especially fiber, is not desirable, because it could reduce the performance of animals; thus, it is important to consider this issue when examining the methane-mitigating potential of $\mathrm{EO}$ or bioactive plant material in general.

Oregano is a perennial herb that grows in Eurasia and North Africa. The EO content in Greek oregano (Origanum vulgare ssp. hirtum) is high and around $4 \%$ of DM (Vokou et al., 1993; Veres et al., 2003; Lukas et al., 2015). A different subspecies of oregano, wild marjoram (Origanum vulgare ssp. vulgare), has naturally lower levels of EO compared with Greek oregano, with concentrations as low as $0.2 \%$ of DM and up to $1 \%$ of DM (Veres et al., 2003; Lukas et al., 2015). Only 2 previous studies have investigated the effect of feeding dried oregano leaf material as a methane mitigation strategy for dairy cows. Tekippe et al. (2011) reported a $40 \%$ decline in hourly methane production when individual cows were fed $500 \mathrm{~g}$ (approximately $17.3 \mathrm{~g}$ of oregano $\mathrm{DM} / \mathrm{kg}$ of dietary $\mathrm{DM}$ and $1.40 \%$ EO in oregano DM) of oregano leaf material (O. vulgare L.) daily. Similarly, Hristov et al. (2013) observed a linear decline in methane production per kilogram of DMI across oregano doses $(0,250,500$, and $750 \mathrm{~g}$ of $O$. vulgare L. leaf material per day corresponding to approximately 8.1, 16.6, and 25.8 $\mathrm{g}$ of oregano $\mathrm{DM} / \mathrm{kg}$ of dietary DM, respectively, and $1.58 \%$ EO in oregano DM), with the highest reduction (36\%) being documented for the $500 \mathrm{~g} / \mathrm{d}$ dose. In both studies, methane production was measured for $8 \mathrm{~h}$ post feeding. Therefore, the methane mitigation observed in those studies may have been overestimated and effects of oregano should also be evaluated over the course of full consecutive days.

The current study used 2 subspecies of oregano with differing EO content and measured methane emission over a 4 -d period. The overall aim was to evaluate the potential of adding dried oregano plant materials to feed as a methane mitigation strategy for dairy cows. In the first experiment (Exp. 1), we examined the effects of oregano plant material (O. vulgare ssp. vulgare) containing naturally low EO contents. We hypothesized that the low levels of EO would not lead to lowered methane production or altered rumen fermentation because EO are assumed to be the active compounds altering rumen fermentation through antimicrobial effects. In the second experiment (Exp. 2) we used dried oregano (O. vulgare ssp. hirtum) plant material with naturally high EO content and examined its effects on methane production, rumen fermentation, apparent nutrient digestibility, and milk fatty acid (FA) composition of lactating dairy cows. We hypothesized that methane production would be lowered, rumen fermentation would be altered, apparent nutrient digestibility (especially NDF) would be reduced, and milk FA composition would be altered by lowered concentrations of short-chain FA when diets containing high EO oregano were fed to lactating dairy cows.

\section{MATERIALS AND METHODS}

\section{Experimental Design}

The experiments were conducted in accordance with the Danish Ministry of Justice Law No. 726 (September 9, 1993) for experimental animals. Experiment 1 was conducted from February 12 to June 3, 2016, and Exp. 2 from January 13 to May 5, 2017. In Exp. 1, dried oregano (O. vulgare ssp. vulgare) plant material (leaves, stalks, and flowers; grown in the Fyn Region of Denmark; location: $\left.55^{\circ} 32^{\prime} 2.5^{\prime \prime} \mathrm{N}, 10^{\circ} 8^{\prime} 12.8^{\prime \prime} \mathrm{E}\right)$ containing naturally low levels of EO was used (Table 1). In Exp. 2, dried oregano (O. vulgare ssp. hirtum) plant material, with naturally high levels of EO, grown at 2 locations in Europe was used. The dried oregano from the 2 locations was mixed as is, with $27 \%$ originating from the Fyn Region of Denmark (leaves, stalks, and flowers; location: $\left.55^{\circ} 18^{\prime} 35.9^{\prime \prime} \mathrm{N}, 10^{\circ} 26^{\prime} 32.6^{\prime \prime} \mathrm{E}\right)$ and $73 \%$ originating from the Argolis Region of Greece (leaves and flowers; location: $37^{\circ} 38^{\prime} 21.5^{\prime \prime} \mathrm{N}, 22^{\circ} 42^{\prime} 18.2^{\prime \prime} \mathrm{E}$ ). Oregano plant material from all locations was harvested when near to full flowering and was then dried and ground. Care was taken during drying, grinding, and storage of the material to ensure the high quality of high EO oregano. The EO content of high EO oregano was routinely determined every 2 wk over the experiment to monitor the stability of the EO content. From this point forward, the dried oregano plant material is referred to as oregano.

Each experiment involved a $4 \times 4$ Latin square design with 4 lactating Danish Holstein dairy cows fed 4 rations with differing oregano content. Each cow received each diet once: control $(\mathbf{C})$, low $(\mathbf{L})$, medium $(\mathbf{M})$, and high $(\mathbf{H})$. In Exp. 1 with low EO oregano, the feed contained $0,18,36$, and $53 \mathrm{~g}$ of oregano $\mathrm{DM} / \mathrm{kg}$ of dietary DM for C, L, M, and H, respectively. In Exp. 2 with high EO oregano, the feed contained 0, 7, 14, and $21 \mathrm{~g}$ of oregano DM $/ \mathrm{kg}$ of dietary DM, for C, L, M, and $\mathrm{H}$, respectively. Oregano was incorporated into the diet by replacing grass/clover silage on a DM basis. The 2 experiments covered a $28-\mathrm{d}$ period, and were divided into adaptation to the diet (from d 1 to 16), digesta collection (from d 17 to 21), and gas measurements (from d 24 to 28). No samples were collected on d 22 and 23. 


\section{Animals and Housing}

Cows were fitted with a rumen cannula, as well as duodenal and ileal simple T-cannulas, to allow for the collection of digesta. The animals were housed in individual tie-stalls covered with mats and sawdust. In Exp. 1, 2 cows were in first parity, 1 cow in second parity, and 1 cow in third parity. At the start of the experiment, average \pm SD milk yield was $35.6 \pm 5.4$ $\mathrm{kg} / \mathrm{d}$, DIM was $158 \pm 81 \mathrm{~d}$, BW was $541 \pm 22 \mathrm{~kg}$, and BCS was $2.81 \pm 0.13$. In Exp. 2, 1 cow was in first parity, 1 cow in second parity, and 2 cows in third parity. Cows had an average milk yield of $27.5 \pm 11.1 \mathrm{~kg} / \mathrm{d}$, were $328 \pm 217$ DIM, had an average BW of $712 \pm 117$ $\mathrm{kg}$, and had an average BCS of $3.06 \pm 0.38$.

\section{Diet and Feeding}

Cows were fed TMR consisting of primary growth grass/clover silage (perennial ryegrass and white clover), maize silage, concentrates, and oregano ( $\mathrm{C}$ diet without oregano; Table 2). The forage:concentrate ratio for all diets in both experiments was 63:37 on a DM basis, with oregano being part of the forage component. The diets were formulated using NorFor (Volden, 2011) and based on an expected milk yield of $9,500 \mathrm{~kg}$ of ECM per year. All rations had a minimum protein content of $15 \mathrm{~g}$ of amino acid $\mathrm{N}$ absorbed in the intestine per megajoule of $\mathrm{NE}_{\mathrm{L}}$ (Volden, 2011). Oregano was integrated into TMR by substituting grass/clover silage on a DM basis (chemical compositions are presented in Table 3). Cows were fed ad libitum with approximately equal portions of TMR at 0800 and $1700 \mathrm{~h}$. At the beginning of each period, cows were gradually introduced to increasing amounts of oregano in the diet to limit the risk of reduced DMI. The oregano content in the diets increased with $17.8 \mathrm{~g} / \mathrm{kg}$ of DM per day up to the desired levels for Exp. 1 and $7.0 \mathrm{~g} / \mathrm{kg}$ of DM per day for Exp. 2. This stepwise increase took 1, 2, and $3 \mathrm{~d}$ for the $\mathrm{L}, \mathrm{M}$, and $\mathrm{H}$ oregano diets, respectively. When cows changed diet from a higher oregano dose to a lower oregano dose, the decrease was not gradual, but immediate. Chromic oxide $\left(\mathrm{Cr}_{2} \mathrm{O}_{3}\right)$ and titanium dioxide $\left(\mathrm{TiO}_{2}\right)$ were used as external markers to deter-

Table 1. Essential oil (EO) composition ${ }^{1}$ of dried oregano plant material and grass/clover silage

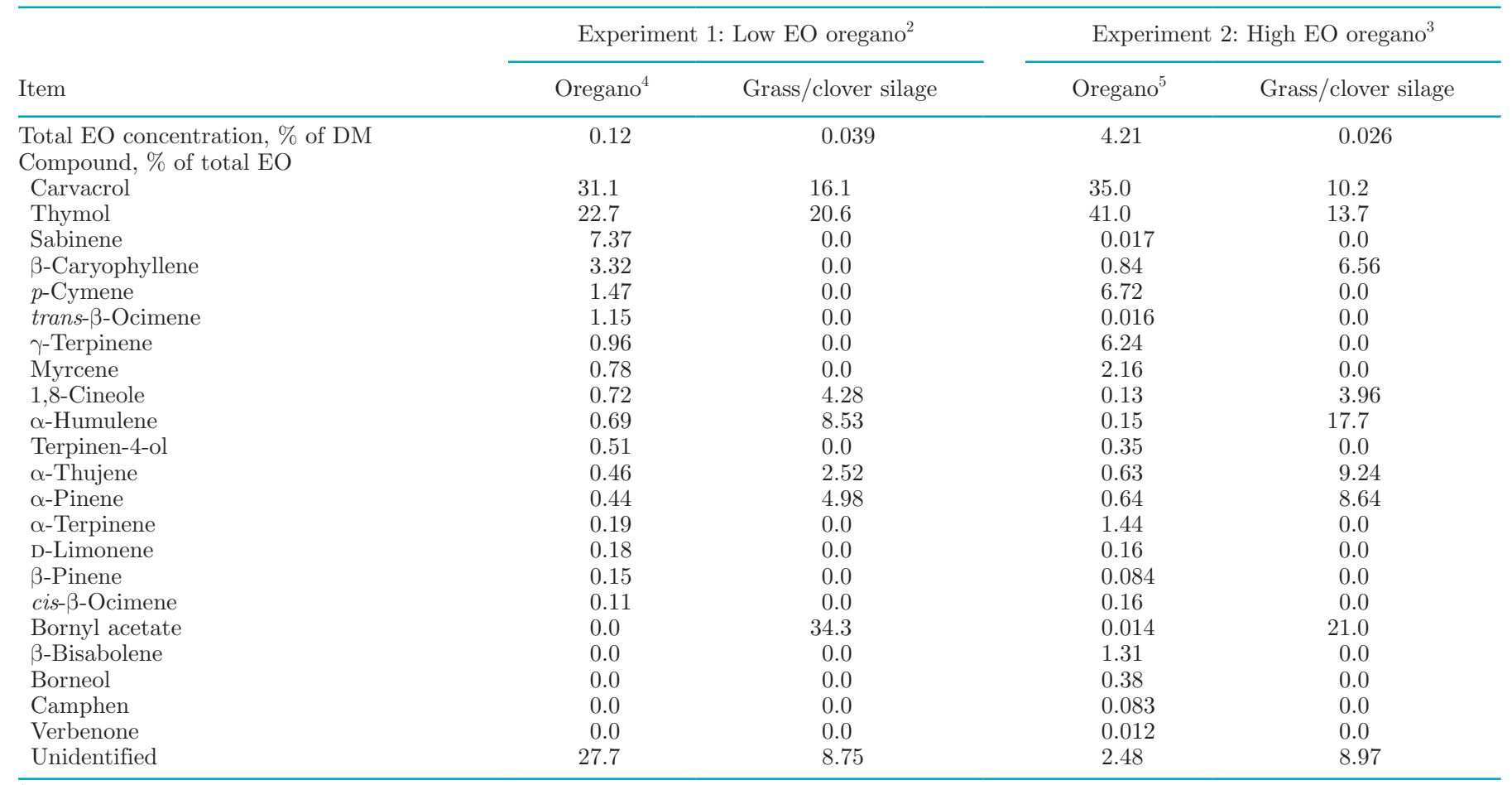

${ }^{1}$ Essential oils were also analyzed in maize silage, spring barley, and soybean meal for both experiments. Traces of EO were only found in the maize silage $(0.0003 \%$ EO of DM) and soybean meal (0.0006\% EO of DM) used in Experiment 1; EO were absent in the spring barley used in Experiment 1 and from all feed ingredients in Experiment 2.

${ }^{2}$ Diets contained $0,18,36$, and $53 \mathrm{~g}$ of oregano DM/ $\mathrm{kg}$ of dietary DM for the control, low, medium, and high oregano diets, respectively.

${ }^{3}$ Diets contained $0,7,14$, and $21 \mathrm{~g}$ of oregano DM/ $\mathrm{kg}$ of dietary DM for control, low, medium, and high oregano diets, respectively.

${ }^{4}$ Origanum vulgare ssp. vulgare.

${ }^{5}$ Origanum vulgare ssp. hirtum. 
Table 2. Dietary composition and analyzed chemical composition (grams per kilogram of DM, unless stated otherwise) of the experimental diets fed to dairy cows

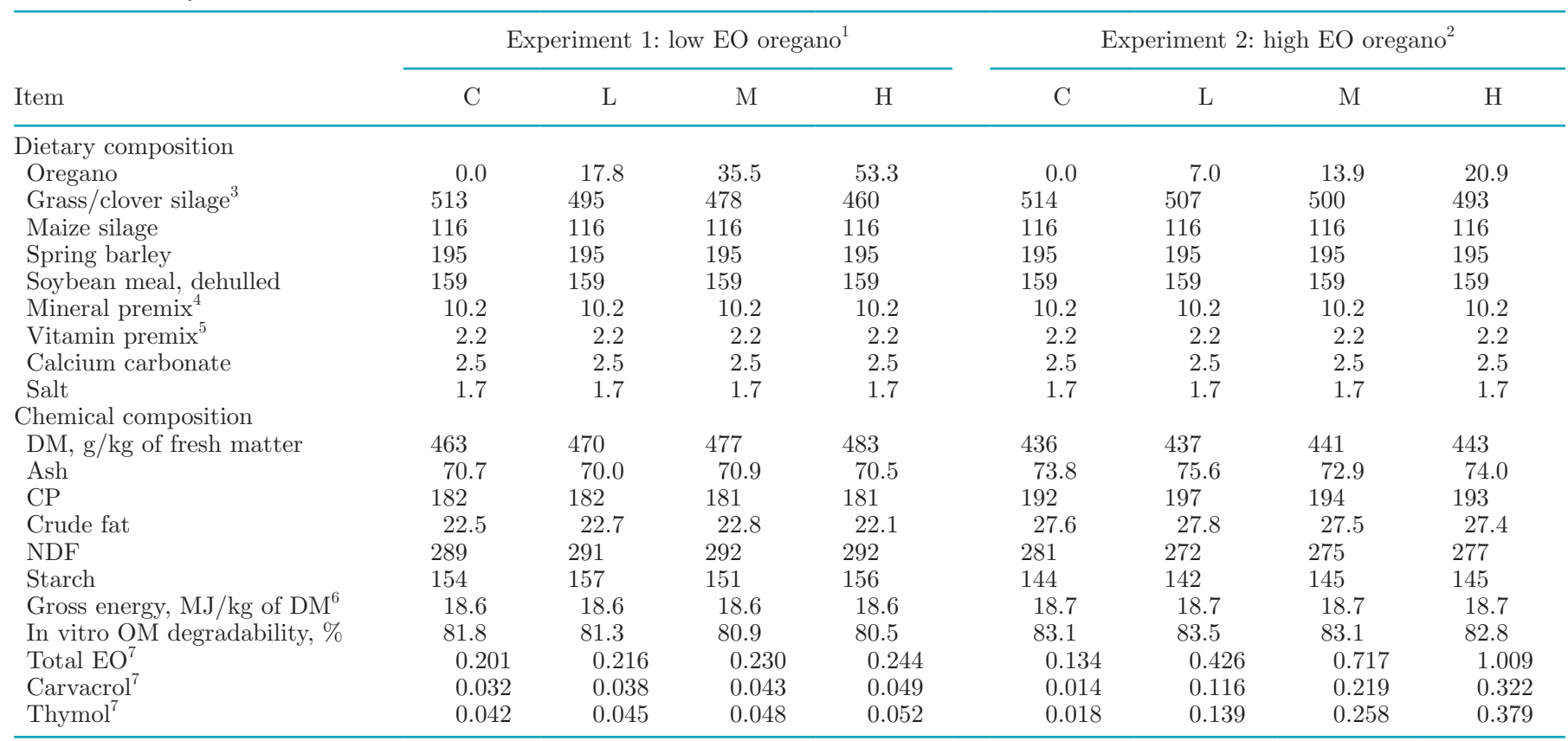

${ }^{1}$ Experiment 1 used Origanum vulgare ssp. vulgare with an EO content of $0.12 \%$ of DM. EO = essential oil; $\mathrm{C}=$ control; $\mathrm{L}=$ low; $\mathrm{M}=$ medium; $\mathrm{H}=$ high.

${ }^{2}$ Experiment 2 used Origanum vulgare ssp. hirtum with an EO content of $4.21 \%$ of DM.

${ }^{3} \mathrm{Grass} /$ clover silage consisted of perennial ryegrass and white clover.

${ }^{4}$ Concentration of vitamins and minerals per kilogram DM of feedstuff: $176 \mathrm{~g}$ of chloride, $140 \mathrm{~g}$ of magnesium, $120 \mathrm{~g}$ of calcium, $120 \mathrm{~g}$ of sodium, $1.5 \mathrm{~g}$ of potassium, $0.5 \mathrm{~g}$ of sulfur, 4,500 $\mathrm{mg}$ of zinc, 4,000 $\mathrm{mg}$ of manganese, 1,500 $\mathrm{mg}$ of copper, $225 \mathrm{mg}$ of iodine, $50 \mathrm{mg}$ of selenium, $25 \mathrm{mg}$ of cobalt, 600,000 IU of vitamin A, 190,000 IU of vitamin $\mathrm{D}_{3}$, and 4,000 IU of vitamin E.

${ }^{5}$ Concentration of vitamins and minerals per $\mathrm{kg}$ of DM of feedstuff: $10 \mathrm{mg}$ of selenium, 5,000,000 IU of vitamin A, 200,000 IU of vitamin D, and $10,000 \mathrm{IU}$ of vitamin $\mathrm{E}$.

${ }^{6}$ Calculated according to NorFor (Volden and Nielsen, 2011).

${ }^{7}$ Calculated EO, carvacrol, and thymol content based on the EO, carvacrol, or thymol content in feed ingredients and dietary proportion of feed ingredients.

mine nutrient flow in the digestive tract. Markers were weighed in degradable paper bags $\left(10 \mathrm{~g}\right.$ of $\mathrm{Cr}_{2} \mathrm{O}_{3}$ and $13 \mathrm{~g}$ of $\mathrm{TiO}_{2}$ ) and were placed in the rumen twice a day during milking at 0700 and $1630 \mathrm{~h}$.

\section{Gas Measurements and Sampling}

Gas exchange was measured for $4 \mathrm{~d}$ using 4 individual transparent polycarbonate respiration chambers based on open circuit indirect calorimetry, as described by Hellwing et al. (2012). The system measured air flow using a mass flow meter (HFM-200 with laminar flow element, Teledyne Hastings Instruments, Hampton, VA; average $\pm \mathrm{SD}$ airflow was $1,952 \pm 60 \mathrm{~L} / \mathrm{min}$ in Exp. 1 and 2,024 $\pm 55 \mathrm{~L} / \mathrm{min}$ in Exp. 2), concentrations of gases (methane, carbon dioxide, oxygen, and hydrogen; Columbus Instruments, Columbus, OH), and temperature, humidity, and pressure (Veng Systems, Roslev, Denmark). The chambers were placed in a square to allow visual contact between cows. Cows were allocated to a specific respiration chamber (same chamber for each cow throughout the experiment) for the first $48 \mathrm{~h}$ of gas measurements and were changed to the chamber along the diagonal for the latter $48 \mathrm{~h}$ of gas measurements. This procedure was implemented to counteract eventual differences in background air composition.

The chamber was cleaned at the same times as the cows were fed and milked. Data measured during opening times were deleted and replaced by the average for all other measurements per cow per period. After the respiration chambers were closed, the feed bins inside the chambers were kept closed for $30 \mathrm{~min}$ to stabilize gas concentrations before the onset of feeding. A scale in the feed bin of the respiration chamber logged feed intake continuously throughout the day from which hourly feed intake could be obtained.

Standard conditions for temperature $\left(0^{\circ} \mathrm{C}\right)$ and pressure $(101.325 \mathrm{kPa})$ were used to calculate gas exchange, and $1 \mathrm{~L}$ of methane was considered to weigh $0.716 \mathrm{~g}$. Recovery of gases was measured before, during, and 
after the experiments by infusing a known amount of pure carbon dioxide or methane into the chambers and comparing it with the amount of accumulated gases measured by the system. Average recovery values $\pm S D$ were used to correct the measured gas concentrations (Exp. 1: $99.9 \pm 0.66 \%$ for methane and $98.0 \pm 0.77 \%$ for carbon dioxide; Exp. 2: $98.7 \pm 1.71 \%$ for methane and $98.0 \pm 1.11 \%$ for carbon dioxide).

Feed intake was determined on a daily basis by collecting refusals. Samples of TMR and refusals were collected daily during digesta collection and gas measurements to determine DM content. Samples of TMR and refusals were collected daily in the digesta sampling week, feed ingredients were collected weekly, and samples were stored at $-20^{\circ} \mathrm{C}$. Pooled samples of TMR, grass/clover silage, and oregano were analyzed for nutrients, and in vitro OM degradability was determined.

Duodenal and ileal content and feces were sampled 12 times over $5 \mathrm{~d}$ : at 1000 and $1800 \mathrm{~h}$ on d 1 ; at 0200 , 1200 , and $2000 \mathrm{~h}$ on d 2; at 0400,1400 , and $2200 \mathrm{~h}$ on $\mathrm{d} 3$; at 0600 and $1600 \mathrm{~h}$ on $\mathrm{d} 4$; and at 0000 and $0800 \mathrm{~h}$ on $\mathrm{d} 5$. Pooled samples were stored at $-20^{\circ} \mathrm{C}$. In Exp. 1 with low EO, the digesta of 1 cow fed the M diet in period 2 could not be collected due to illness (infection in the intestines). Rumen liquid was collected in connection with digesta sampling at 0600, 1200, 1800, and $0000 \mathrm{~h}$. Rumen liquid (30-40 mL) was sampled from the ventral ruminal sac using a $50-\mathrm{mL}$ syringe attached to a 90-cm steel rumen sampler (Bar Diamond Inc., Parma, ID). Rumen $\mathrm{pH}$ was measured directly after collection by a digital pH meter (Meterlab PHM 220, Radiometer, Brønshøj, Denmark), and samples were stored frozen until further analysis for VFA, lactate, and ammonia concentration. Rumen liquid (2 L) was also collected on the last day in the digesta collection week at $1100 \mathrm{~h}$ to harvest microbes. Rumen liquid was collected from the liquid phase using a cup, filtered over 2 layers of cheesecloth, and transferred to prewarmed thermos bottles. Samples were handled directly in the laboratory according to Brask et al. (2015). In brief, feed particles and protozoa were removed by a double centrifugation at $500 \times g$ for $5 \mathrm{~min}$ at $3^{\circ} \mathrm{C}$. Next, the supernatant was collected and centrifuged at 17,300 $\times$ $g$ for $20 \mathrm{~min}$ at $3^{\circ} \mathrm{C}$. The pellet was then collected and resuspended in $200 \mathrm{~mL}$ of $\mathrm{NaCl}(9 \%)$ and centrifuged at $17,300 \times g$ for $20 \mathrm{~min}$ at $3^{\circ} \mathrm{C}$. The resulting pellet (microbial matter) was stored at $-20^{\circ} \mathrm{C}$. Finally, the microbial matter was freeze-dried and analyzed for ash, nitrogen, and purine content. The 12 duodenal $(0.5 \mathrm{~L})$ and ileal $(0.2 \mathrm{~L})$ samples were collected by mounting a plastic bag on the cannula, and the bags were filled by bowel movement. Samples were pooled at the time of collection. The 12 fecal ( $\sim 350 \mathrm{~g})$ samples were collected during voluntary defecation or from the rectum. Grab samples of rumen material of the cows in Exp. 2 (16 observations) were taken to investigate the rumen bacterial community structure. Grab samples of rumen material were taken from 8 locations in the rumen and pooled on the last day of each experimental period at $1100 \mathrm{~h}$.

Milk yield was recorded at each milking (0700 and $1630 \mathrm{~h}$ ) during digesta collection and gas measurements. Milk samples were collected from consecutive morning and afternoon milkings (6 milkings for Exp. 1 and 4 milkings for Exp. 2) during the digesta collection week and for all other weeks at 2 subsequent milkings. Milk was analyzed for fat, protein, and lactose content.

Body weight was measured at a platform scale at the start of the experiments, in each period before cows entered the respiration chambers, and after cows left

Table 3. Chemical composition (grams per kilogram of DM, unless stated otherwise) of dried oregano plant material and grass/clover silage ${ }^{1}$ fed to dairy cows

\begin{tabular}{|c|c|c|c|c|}
\hline \multirow[b]{2}{*}{ Item } & \multicolumn{2}{|c|}{ Experiment 1: low EO oregano ${ }^{2}$} & \multicolumn{2}{|c|}{ Experiment 2: high EO oregano ${ }^{3}$} \\
\hline & Oregano & Grass/clover silage & Oregano & Grass/clover silage \\
\hline$\overline{\mathrm{DM}}, \mathrm{g} / \mathrm{kg}$ of fresh matter & 882 & 369 & 891 & 339 \\
\hline Ash & 85.7 & 84.0 & 108 & 80.5 \\
\hline $\mathrm{CP}$ & 81.9 & 139 & 140 & 163 \\
\hline Crude fat & 18.9 & 24.4 & 44.1 & 30.2 \\
\hline NDF & 440 & 406 & 243 & 374 \\
\hline $\mathrm{iNDF}^{4}$ & 289 & 50.4 & 112 & 44.0 \\
\hline Starch & 13.3 & 1.96 & 11.3 & 2.13 \\
\hline In vitro OM degradability & 43.6 & 77.6 & 50.2 & 81.0 \\
\hline
\end{tabular}

${ }^{1}$ Grass/clover silage consisted of perennial ryegrass and white clover.

${ }^{2}$ Experiment 1 used Origanum vulgare ssp. vulgare with an essential oil (EO) content of $0.12 \%$ of DM. Diets contained $0,18,36$, and $53 \mathrm{~g}$ of oregano $\mathrm{DM} / \mathrm{kg}$ of dietary DM for control, low, medium, and high oregano diets, respectively.

${ }^{3}$ Experiment 2 used Origanum vulgare ssp. hirtum with an EO content of $4.21 \%$ of DM. Diets contained 0, 7, 14 , and $21 \mathrm{~g}$ of oregano $\mathrm{DM} / \mathrm{kg}$ of dietary DM for control, low, medium, and high oregano diets, respectively. ${ }^{4} \mathrm{iNDF}=$ indigestible neutral detergent fiber. 
the chambers. Body condition score was determined on the day the cows left the chambers and assessed by the same person throughout each experiment.

\section{Laboratory Analyses}

Dry matter content of fresh feed and residue samples was determined by drying at $60^{\circ} \mathrm{C}$ for $48 \mathrm{~h}$ (AOAC International, 2000). Feed and digesta samples were freeze-dried and ground on a 1-mm screen, except for a $0.5-\mathrm{mm}$ screen used for analysis of starch and a $1.5-\mathrm{mm}$ screen on a cutter mill for the analysis of indigestible neutral detergent fiber (iNDF). Ash content was determined by combustion at $525^{\circ} \mathrm{C}$ for $6 \mathrm{~h}$. Nitrogen content was analyzed by the Dumas method (Hansen, 1989), using a Vario MAX CN (Elementar Analysensysteme GmbH, Hanau, Germany). Nitrogen $\times 6.25$ was used to obtain CP. Crude fat was analyzed by hydrolyzing the samples with hydrochloric acid (Stoldt, 1952) and extraction of crude fat using petroleum ether and a Soxtec 2050 (Foss Analytical, Hillerød, Denmark). Starch was digested with heat-stable $\alpha$-amylase and amyloglucosidase, and the reaction was subsequently assayed for glucose (Kristensen et al., 2007) by using a YSI model 2900 analyzer (YSI Inc., Yellow Springs, $\mathrm{OH}$ ). Neutral detergent fiber was treated with heatstable amylase and sodium sulfite using a Fibertec M6 System (Foss Analytical, Hillerød, Denmark) and reported as ash-free NDF (Mertens, 2002). Indigestible NDF was determined after incubation for $288 \mathrm{~h}(12 \mathrm{~d})$ in the rumen of 3 dry cows, using Dacron bags ( 1 bag per cow for each sample) with a pore size of $12 \mu \mathrm{m}$, and was expressed as residual NDF (Krämer et al., 2012). Dry cows were fed a standard ration at maintenance level, as described by Brask et al. (2013). The in vitro OM degradability of TMR, oregano, and grass/clover silage as separate substrates (0.5 g per sample) was determined in duplicate by $48 \mathrm{~h}$ of incubation in rumen liquid of donor cows $(55 \mathrm{~mL}$ of solution consisting of 1 part rumen liquid and 5 parts buffer) followed by $48 \mathrm{~h}$ of digestion in pepsin and hydrochloric acid (Tilley and Terry, 1963).

The total EO content and individual EO compounds (volatile terpenes, i.e., lipophilic terpenoids, phenylpropanoids, or short-chain aliphatic hydrocarbon derivatives) in oregano, fresh silage, and concentrates were assayed using original standards (Sigma-Aldrich, Darmstadt, Germany) and gas chromatographic analyses. The volatile terpenes were extracted and quantified according to Grevsen et al. (2009) using a Focus gas chromatograph (Thermo Fisher Scientific, Waltham, MA) equipped with a Chrompack WCOT fused silica capillary column $(50 \mathrm{~m} \times 0.25 \mathrm{~mm}$ i.d., film thickness $=0.2 \mu \mathrm{m}$ liquid phase: $\mathrm{CP}-$ Wax $52 \mathrm{CB}$;
Chrompack, Middelburg, the Netherlands) and a split/ splitless injector and flame ionization detector (Thermo Fisher Scientific). Chromic oxide in digesta and feces was analyzed by oxidation to chromate and afterward determined spectrophotometrically, using Lamba 900 equipment (PerkinElmer Inc., Waltham, MA; Schürch et al., 1950). Titanium dioxide in digesta and feces was analyzed according to Myers et al. (2004). In brief, titanium dioxide was treated with sulfuric acid and hydrogen peroxide, with absorbance being subsequently measured spectrophotometrically (Lamba 900, PerkinElmer Inc.). A modification to the method of Myers et al. (2004) was made by adding $15 \mathrm{~mL}$ of $30 \%$ hydrogen peroxide instead of $10 \mathrm{~mL}$, and 5 additional drops were added before absorbance was measured. Titanium dioxide was also analyzed in feed, but a correction for titanium dioxide with feed was not made, because the titanium dioxide concentration in most samples of both experiments was below the detection limit of the analysis (detection limit of $0.10 \mathrm{~g}$ of $\mathrm{TiO}_{2} /$ $\mathrm{kg}$ of DM). The total purine content in microbial matter and duodenal content was analyzed according to Zinn and Owens (1986), as modified by Thode (1997). Perchloric acid was added to the samples to hydrolyze the nucleotides into purines, after which purines were precipitated into complexes with silver nitrate and measured spectrophotometrically (Lamba 900, PerkinElmer Inc.). For analysis of ammonia concentration in rumen liquid, samples were alkalinized with potassium hydroxide, distilled, and titrated using a Kjeltec 2400 (Foss Analytical; Brask et al., 2013). Concentrations of VFA and lactate in rumen liquid were analyzed according to Jensen et al. (1995) and Canibe et al. (2007), respectively, using a Hewlett Packard gas chromatograph model 6890 (Agilent Technologies Inc., Wilmington, DE) with a flame ionization detector and a $30-\mathrm{m}$ SGE BP1 column (Scientific Instrument Services Inc., Ringoes, NJ). Grab samples of rumen material were freeze-dried to determine the rumen bacterial community structure, and DNA was extracted and profiled by Illumina amplicon sequencing of the $16 \mathrm{~S}$ rRNA gene (V3-V4), using universal primers (Bac341F and Bac805R; Klindworth et al., 2013). A total of 479,307 sequences were analyzed with the QIIME2 pipeline (Bolyen et al., 2018). After quality filtering, merging, denoising, and chimera removal through use of DADA2 (Callahan et al., 2016), 254,590 good quality sequences were clustered into 3,000 features.

Milk protein, lactose (as lactose monohydrate), and fat content were determined using an infrared analyzer (MilkoScan Msc4000, Foss Analytical) at Eurofins Steins Laboratories (Vejen, Denmark). Fatty acids in milk were analyzed by isolating milk fat by centrifugation and methylation using sodium methylate accord- 
ing to Larsen et al. (2013), with the modification of using heptane as the solvent instead of pentane. Methyl esters were analyzed using a gas chromatograph (Agilent 7890A) with a flame ionization detector (Agilent Technologies Inc., Santa Clara, CA) and Rtx-65TG column $(2.5 \mathrm{~m}, 0.25 \mathrm{~mm}$ i.d., 0.10- $\mu \mathrm{m}$ film thickness; Restek, Bellefonte, PA).

\section{Calculations and Statistical Analyses}

Dry matter intake was calculated as the amount of DM of refusals subtracted from the DM offered. Nutrient intakes of OM, CP, crude fat, and NDF were calculated by multiplying DMI with the respective nutrient content in feed. The duodenal, ileal, and fecal DM flow was calculated for both markers separately by dividing the marker dosage with the marker concentration in duodenal, ileal, and fecal content, respectively (Owens and Hanson, 1992), and was averaged across markers. The nutrient flow of $\mathrm{CP}$, crude fat, and NDF in the duodenum, ileum, and feces was calculated from the DM flow and respective nutrient concentration in each section of the digestive tract. Nutrient intake and flow were used to calculate apparent nutrient digestibility in different sections of the digestive tract. Gross energy intake was calculated according to NorFor (Volden and Nielsen, 2011). Microbial CP synthesis was calculated from the nitrogen and purine concentration in rumenisolated bacteria, purine concentration in duodenal content, and DM flow in the duodenum (Lund et al., 2003). Microbial efficiency was calculated as microbial $\mathrm{CP}$ flow in the duodenum divided by true rumen digested OM, which was calculated as OM intake with feed minus duodenal OM flow (corrected for microbial OM flow at duodenum). Energy-corrected milk yield $(3.14 \mathrm{MJ} / \mathrm{kg})$ was calculated as ECM yield $(\mathrm{kg} / \mathrm{d})=$ milk yield $(\mathrm{kg} / \mathrm{d}) \times\{[38.3 \times$ milk fat $(\mathrm{g} / \mathrm{kg})+24.2 \times$ milk protein $(\mathrm{g} / \mathrm{kg})+15.71 \times$ milk lactose $(\mathrm{g} / \mathrm{kg})+$ $20.7] / 3,140\}$, where lactose was lactose monohydrate (Sjaunja et al., 1991).

Observations of all variables were averaged within cow and period to obtain 16 observations for the statistical analysis in total, except for some variables in Exp. 1 for which some observations were missing. Due to the illness (infection in the intestines) of 1 cow receiving the $\mathrm{M}$ diet in Exp. 1, 15 observations in total (4, 4, 3, and 4 observations for the $\mathrm{C}, \mathrm{L}, \mathrm{M}$, and $\mathrm{H}$ diet, respectively) were used for measures obtained during the digesta collection week (DMI and nutrient intake). Fourteen observations in total $(4,4,3$, and 3 observations for the $\mathrm{C}, \mathrm{L}, \mathrm{M}$, and $\mathrm{H}$ diet, respectively) were used for apparent nutrient digestibility, because of an erroneously low duodenal DM flow caused by marker problems after illness of the same cow fed the $\mathrm{H}$ diet in Exp. 1 (samples were identified based on a high restricted likelihood distance and internally studentized residuals above 2 ). For the apparent NDF digestibility in the small and large intestine, 13 observations in total $(4,4,2$, and 3 observations for the $\mathrm{C}, \mathrm{L}, \mathrm{M}$, and $\mathrm{H}$ diet, respectively) were used due to an erroneously low NDF content in the ileal content of another cow fed the $\mathrm{M}$ diet (the sample was identified based on incorrect positive NDF digestibility in the small intestine and a negative NDF digestibility in the large intestine). Because of the low number of observations used for digestibility, especially for NDF digestibility in the small and large intestine, results should be interpreted with caution.

The statistical analyses were performed for each experiment separately. Proc Mixed in SAS (version 9.3, SAS Institute Inc., Cary, NC) was used to analyze the effects of feeding oregano on the variables using diet $(\mathrm{C}, \mathrm{L}, \mathrm{M}$, and $\mathrm{H})$ and period (1-4) as fixed effects and cow as a random effect. The degrees of freedom (df) estimation method was containment. Linear, quadratic, and cubic orthogonal polynomial contrasts were used to analyze the effects of diet. Proc Mixed was also used to analyze the effects of diet on methane production in grams per hour and DMI in kilograms per hour during $8 \mathrm{~h}$ post morning feeding for Exp. 2. Diet, period, time, and the interaction between diet and time were considered fixed effects and cow was considered a random effect. The model included a repeated statement for time with heterogeneous first-order autoregressive $\operatorname{ARH}(1)$ as covariance structure, which was chosen based on the lowest Akaike information criterion values. The paired samples $t$-test was used to evaluate differences in DMI between the digesta collection week and gas measurement week. Beta group significance of the bacterial community structure was determined on both weighted and unweighted UniFrac matrices with PERMANOVA analysis (999 permutations), but these data are not presented because no differences in the major and minor bacterial community members were found.

Least squares means and SEM are presented in the tables. Significance was declared at $P \leq 0.05$ and a tendency at $0.05<P \leq 0.10$.

\section{RESULTS}

\section{Feed Characteristics}

The experimental diets were formulated by replacing part of the grass/clover silage with oregano on a DM basis, which produced similar DM content across treatments in Exp. 2; however, the DM content of the diets in Exp. 1 were slightly different (Table 2). Despite the grass/clover silage and oregano having different chemi- 
cal compositions (Table 3), the chemical compositions of the diets were not markedly different across treatments. In vitro OM degradability was lower for oregano compared with grass/clover silage (Table 3). The total EO content of oregano was $0.12 \%$ of oregano DM for Exp. 1 and $4.21 \%$ of DM for Exp. 2, with carvacrol and thymol being the predominant compounds in EO (Table 1).

\section{Nutrient Intake and Apparent Nutrient Digestibility}

Experiment 1. The level of dietary inclusion of low EO oregano did not affect the DMI during digesta collection and OM intake (Table 4). Dry matter intake (mean difference $\pm \mathrm{SD}$ ) was $1.15 \pm 0.66 \mathrm{~kg} / \mathrm{d}$ higher $(P<0.001)$ during gas measurements compared with during digesta collection.

The inclusion level of oregano did not influence the apparent digestibility of DM and OM in the rumen, small intestine, and large intestine. Apparent total-tract digestibility of DM and OM decreased in a linear (for both $P=0.001)$ and cubic way $(P=0.04$ for $\mathrm{DM}$ and $P$ $=0.03$ for $\mathrm{OM}$ ), with the digestibility coefficients of the $\mathrm{M}$ and $\mathrm{H}$ diets being lower than those for $\mathrm{C}$ and $\mathrm{L}$ diets.

Apparent CP digestibility in the small intestine decreased linearly $(P=0.02)$ and tended to respond quadratically $(P=0.09)$ with increasing doses of low EO oregano, with the $\mathrm{H}$ diet having the lowest digestibility coefficient. In comparison, the $\mathrm{C}, \mathrm{L}$, and $\mathrm{M}$ diets had similar digestibility coefficients. Apparent CP digestibility in the large intestine responded quadratically $(P$ $=0.02$ ) with increasing doses of oregano. Moreover, the inclusion level of low EO oregano did not affect $\mathrm{CP}$ intake and the apparent digestibility of $\mathrm{CP}$ in the rumen and total tract.

Feeding increasing levels of low EO oregano did not affect the intake and apparent digestibility of NDF in the rumen, small intestine, and large intestine. However, the apparent total-tract NDF digestibility decreased linearly $(P=0.001)$, with $\mathrm{C}$ and $\mathrm{L}$ diets having higher digestibility compared with the $\mathrm{H}$ diet.

Experiment 2. Increased levels of high EO oregano did not affect DMI during digesta collection (Table 4). No difference was found between DMI during digesta collection and DMI during gas measurements (mean difference $\pm \mathrm{SD}$ of $0.038 \pm 0.66 \mathrm{~kg} / \mathrm{d}, P=0.82)$. Hourly DMI analyzed for $8 \mathrm{~h}$ post morning feeding was affected by time $(P<0.001)$, but it was not affected by $\operatorname{diet}(P=0.74)$ or the interaction between diet and time $(P=0.25$; data not presented $)$.

Nutrient intake of $\mathrm{OM}$ and $\mathrm{CP}$ did not differ between diets. Neutral detergent fiber intake responded cubically $(P=0.04)$ with increasing doses of dietary oregano. Feeding increasing doses of oregano was ac- companied by lowered apparent total-tract digestibility of DM, OM, and NDF in a quadratic (for all $P=0.03$ ) and cubic way $(P$-values of $0.05,0.03$, and 0.04 for DM, $\mathrm{OM}$, and NDF, respectively). Apparent total-tract digestibility of $\mathrm{CP}$ was lowered linearly $(P=0.001)$ and cubically $(P=0.001)$, and tended to respond quadratically $(P=0.06)$, with increasing doses of oregano. Furthermore, the inclusion level of high EO oregano did not affect the apparent nutrient digestibility of DM, $\mathrm{OM}, \mathrm{CP}$, and NDF in the rumen, small intestine, and large intestine.

\section{Rumen Fermentation}

Experiment 1. Feeding oregano with low levels of EO had no effect on rumen $\mathrm{pH}$, rumen ammonia and lactate concentrations, total VFA concentration, molar proportions of acetate and propionate, and acetate-topropionate (A:P) ratio (Table 5). The butyrate molar proportion increased linearly $(P=0.01)$ and quadratically $(P=0.03)$ with increasing oregano content in the diet. Furthermore, microbial CP synthesis decreased linearly $(P=0.02)$ and tended to respond quadratically $(P=0.08)$, with the lowest value observed for the $\mathrm{H}$ diet. The inclusion level of low EO oregano did not affect microbial efficiency.

Experiment 2. The inclusion level of high EO oregano did not affect rumen $\mathrm{pH}$; concentrations of total VFA, ammonia, and lactate; VFA molar proportions; A:P ratio; microbial CP synthesis; and microbial efficiency (Table 5). In addition, no differences in the major and minor bacterial community members were found (results not presented).

\section{Gas Exchange}

Experiment 1. Feeding low EO oregano did not affect methane production (grams per day, grams per kilogram of DMI, grams per kilogram ECM, and percentage of gross energy intake; Table 6). Hydrogen production increased linearly $(P=0.04)$ with increasing oregano doses. Feeding oregano did not affect carbon dioxide production or oxygen consumption.

Experiment 2. Feeding increasing doses of high EO oregano did not affect methane production (grams per kilogram of DMI, grams per kilogram ECM, and percentage of gross energy intake). However, a cubic response $(P=0.03)$ for lowest daily methane production (grams per day) was found in the $\mathrm{L}$ and $\mathrm{H}$ diets (Table 6). Hourly methane production over 24 $\mathrm{h}$ showed no marked differences between diets (Figure 1). When analyzing hourly methane production for $8 \mathrm{~h}$ post morning feeding, time $(P=0.05)$ and the interaction between diet and time $(P=0.001)$ affected hourly 
Table 4. Intake and apparent digestibility of nutrients in the rumen, small intestine, large intestine, and total tract ${ }^{1}$ of dairy cows fed different levels of dried oregano plant material

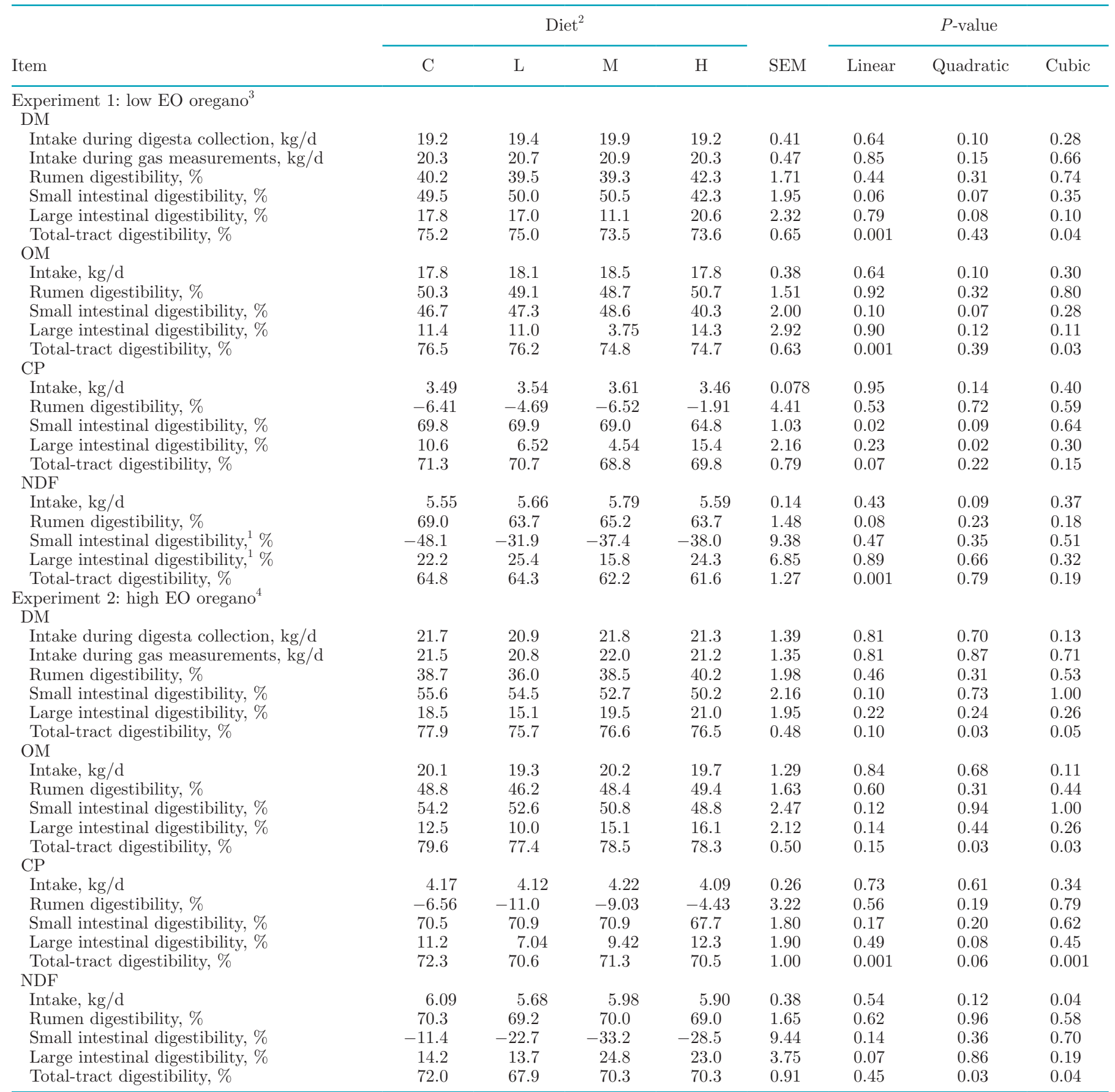

${ }^{1}$ For experiment 1: DMI during gas measurements is based on 16 observations in total and DMI during digesta collection, and nutrient intakes are based on 15 observations in total $(4,4,3$, and 4 observations for the $\mathrm{C}, \mathrm{L}, \mathrm{M}$, and $\mathrm{H}$ diet, respectively) instead of 16 . Coefficients for apparent nutrient digestibility are based on 14 observations in total $(4,4,3$, and 3 observations for the $\mathrm{C}$, L, M, and $\mathrm{H}$ diet, respectively) instead of 16, except for apparent NDF digestibility in the small and large intestine for which 13 observations in total $(4,4,2$, and 3 observations for the $\mathrm{C}, \mathrm{L}, \mathrm{M}$, and $\mathrm{H}$ diet, respectively) instead of 16 were used; thus, the results should be interpreted with caution. For experiment 2 , all 16 observations were used.

${ }^{2} \mathrm{C}=$ control diet; $\mathrm{L}=$ low oregano diet; $\mathrm{M}=$ medium oregano diet; $\mathrm{H}=$ high oregano diet.

${ }^{3}$ Experiment 1 used Origanum vulgare ssp. vulgare with an essential oil (EO) content of $0.12 \%$ of DM. Diets contained 0, 18, 36, and 53 g of oregano $\mathrm{DM} / \mathrm{kg}$ of dietary $\mathrm{DM}$ for $\mathrm{C}, \mathrm{L}, \mathrm{M}$, and $\mathrm{H}$, respectively.

${ }^{4}$ Experiment 2 used Origanum vulgare ssp. hirtum with an EO content of $4.21 \%$ of DM. Diets contained 0, 7, 14, and $21 \mathrm{~g}$ of oregano DM/kg of dietary DM for $\mathrm{C}, \mathrm{L}, \mathrm{M}$, and $\mathrm{H}$, respectively. 
Table 5. Rumen fermentation characteristics of dairy cows fed different levels of dried oregano plant material

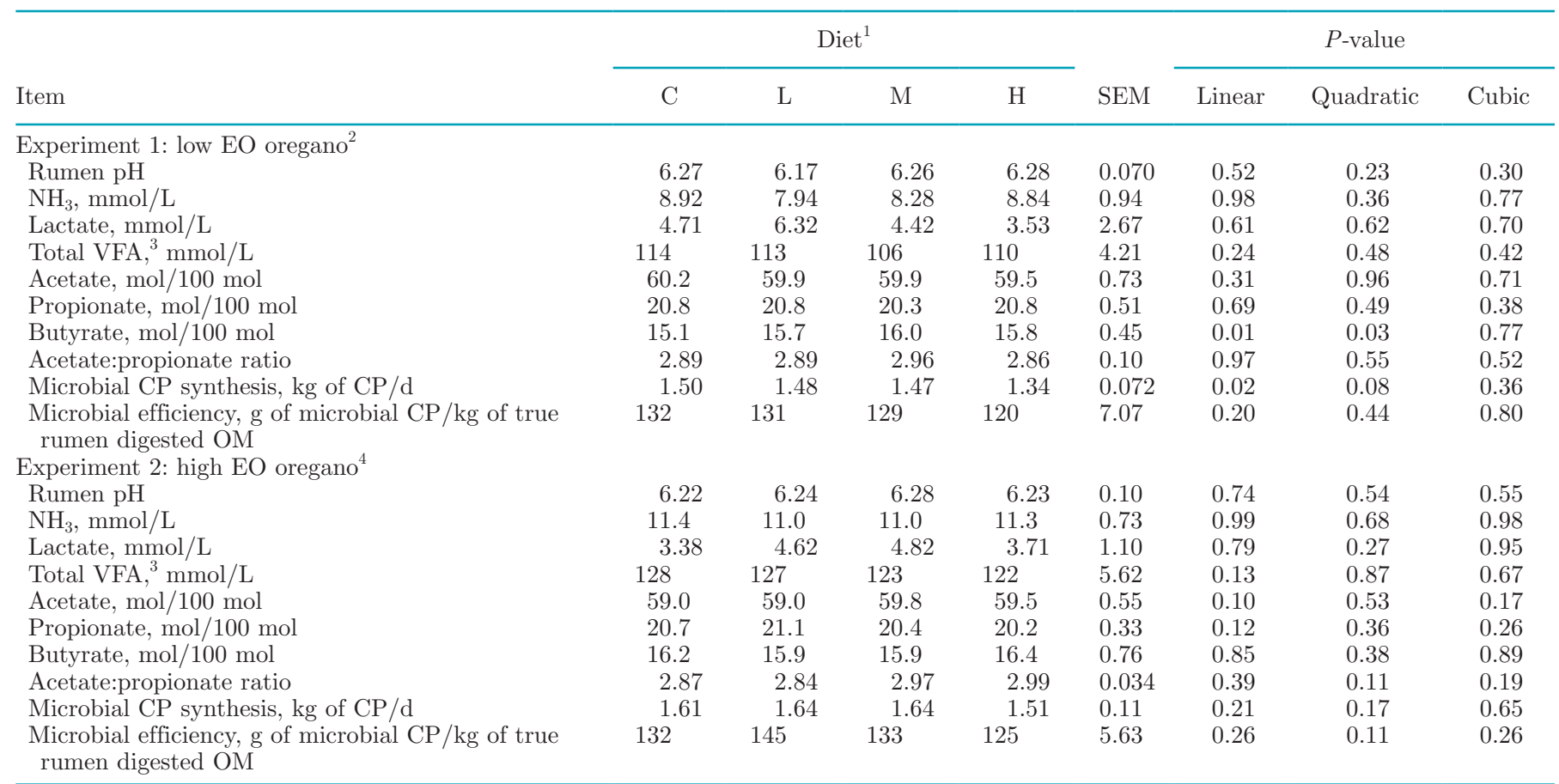

${ }^{1} \mathrm{C}=$ control diet; $\mathrm{L}=$ low oregano diet; $\mathrm{M}=$ medium oregano diet; $\mathrm{H}=$ high oregano diet.

${ }^{2}$ Experiment 1 used Origanum vulgare ssp. vulgare with an essential oil (EO) content of $0.12 \%$ of DM. Diets contained 0 , 18, 36, and 53 g of oregano $\mathrm{DM} / \mathrm{kg}$ of dietary $\mathrm{DM}$, for $\mathrm{C}, \mathrm{L}, \mathrm{M}$, and $\mathrm{H}$, respectively.

${ }^{3}$ Total VFA is the sum of acetate, propionate, butyrate, formate, valerate, iso-butyrate, iso-valerate, caproate, heptanate, benzoate, and succinate concentrations. Benzoate was not present in the rumen liquid samples of experiment 1.

${ }^{4}$ Experiment 2 used Origanum vulgare ssp. hirtum with an EO content of 4.21\% of DM. Diets contained 0, 7, 14, and 21 g of oregano DM/kg of dietary $\mathrm{DM}$ for $\mathrm{C}, \mathrm{L}, \mathrm{M}$, and $\mathrm{H}$, respectively.

Table 6. Gas exchange of dairy cows fed different levels of dried oregano plant material

\begin{tabular}{|c|c|c|c|c|c|c|c|c|}
\hline \multirow[b]{2}{*}{ Item } & \multicolumn{4}{|c|}{$\operatorname{Diet}^{1}$} & \multirow[b]{2}{*}{ SEM } & \multicolumn{3}{|c|}{$P$-value } \\
\hline & $\mathrm{C}$ & $\mathrm{L}$ & M & $\mathrm{H}$ & & Linear & Quadratic & Cubic \\
\hline \multicolumn{9}{|c|}{ Experiment 1: low EO oregano $^{2}$} \\
\hline $\mathrm{CH}_{4}, \mathrm{~g} / \mathrm{d}$ & 461 & 455 & 464 & 451 & 11.1 & 0.46 & 0.63 & 0.22 \\
\hline $\mathrm{CH}_{4}, \mathrm{~g} / \mathrm{kg}$ of DMI & 22.8 & 22.0 & 22.2 & 22.2 & 0.71 & 0.27 & 0.22 & 0.37 \\
\hline $\mathrm{CH}_{4}, \mathrm{~g} / \mathrm{kg}$ of $\mathrm{ECM}$ & 16.8 & 15.4 & 15.9 & 16.0 & 0.86 & 0.40 & 0.16 & 0.37 \\
\hline $\mathrm{CH}_{4}, \%$ of $\mathrm{GEI}^{3}$ & 6.73 & 6.49 & 6.56 & 6.56 & 0.20 & 0.29 & 0.20 & 0.35 \\
\hline $\mathrm{O}_{2}$ consumption, $\mathrm{L} / \mathrm{d}$ & 6,108 & 6,232 & 6,188 & 6,033 & 149 & 0.32 & 0.05 & 0.83 \\
\hline \multicolumn{9}{|c|}{ Experiment 2 : high EO oregano ${ }^{4}$} \\
\hline $\mathrm{CH}_{4}, \mathrm{~g} / \mathrm{d}$ & 502 & 487 & 520 & 485 & 32.0 & 0.70 & 0.30 & 0.03 \\
\hline $\mathrm{CH}_{4}, \mathrm{~g} / \mathrm{kg}$ of DMI & 23.4 & 23.4 & 23.6 & 23.0 & 0.46 & 0.60 & 0.47 & 0.71 \\
\hline $\mathrm{CH}_{4}, \mathrm{~g} / \mathrm{kg}$ of ECM & 21.4 & 21.9 & 21.3 & 22.6 & 3.64 & 0.56 & 0.71 & 0.56 \\
\hline $\mathrm{CH}_{4}, \%$ of GEI & 6.87 & 6.89 & 6.92 & 6.76 & 0.14 & 0.60 & 0.50 & 0.76 \\
\hline $\mathrm{H}_{2}, \mathrm{~L} / \mathrm{d}$ & 6.56 & 7.11 & 7.46 & 6.66 & 0.88 & 0.74 & 0.16 & 0.62 \\
\hline
\end{tabular}

${ }^{1} \mathrm{C}=$ control diet; $\mathrm{L}=$ low oregano diet; $\mathrm{M}=$ medium oregano diet; $\mathrm{H}=$ high oregano diet.

${ }^{2}$ Experiment 1 used Origanum vulgare ssp. vulgare with an essential oil (EO) content of $0.12 \%$ of DM. Diets contained 0, 18, 36, and 53 g of oregano $\mathrm{DM} / \mathrm{kg}$ of dietary $\mathrm{DM}$ for $\mathrm{C}, \mathrm{L}, \mathrm{M}$, and $\mathrm{H}$, respectively.

${ }^{3} \mathrm{GEI}=$ gross energy intake.

${ }^{4}$ Experiment 2 used Origanum vulgare ssp. hirtum with an EO content of $4.21 \%$ of DM. Diets contained 0, 7, 14, and $21 \mathrm{~g}$ of oregano DM/kg of dietary DM for C, L, M, and $\mathrm{H}$, respectively. 
Table 7. Milk yield and composition of dairy cows fed different levels of dried oregano plant material

\begin{tabular}{|c|c|c|c|c|c|c|c|c|}
\hline Item & \multicolumn{4}{|c|}{ Diet $^{1}$} & SEM & \multicolumn{3}{|c|}{$P$-value } \\
\hline \multicolumn{9}{|l|}{ Experiment 1: low EO oregano ${ }^{2}$} \\
\hline ECM yield, $\mathrm{kg} / \mathrm{d}$ & 27.5 & 30.2 & 29.5 & 28.3 & 1.58 & 0.69 & 0.11 & 0.55 \\
\hline Fat, $\%$ & 4.22 & 4.34 & 4.03 & 4.23 & 0.47 & 0.65 & 0.77 & 0.17 \\
\hline Protein, \% & 3.54 & 3.39 & 3.38 & 3.53 & 0.29 & 0.88 & 0.06 & 0.92 \\
\hline Milk yield, $\mathrm{kg} / \mathrm{d}$ & 24.1 & 23.2 & 23.3 & 23.2 & 5.17 & 0.53 & 0.64 & 0.74 \\
\hline ECM yield, $\mathrm{kg} / \mathrm{d}$ & 25.6 & 24.4 & 25.7 & 24.8 & 4.57 & 0.74 & 0.81 & 0.21 \\
\hline Fat, $\%$ & 4.74 & 4.69 & 4.79 & 4.80 & 0.36 & 0.33 & 0.62 & 0.41 \\
\hline Protein, \% & 3.81 & 3.84 & 3.83 & 3.74 & 0.26 & 0.21 & 0.13 & 0.77 \\
\hline Lactose, \% & 4.31 & 4.32 & 4.30 & 4.34 & 0.076 & 0.35 & 0.22 & 0.21 \\
\hline FCE, $\mathrm{kg}$ of $\mathrm{ECM} / \mathrm{kg}$ of DMI & 1.16 & 1.15 & 1.16 & 1.13 & 0.16 & 0.50 & 0.84 & 0.63 \\
\hline
\end{tabular}

${ }^{1} \mathrm{C}=$ control diet $; \mathrm{L}=$ low oregano $\operatorname{diet} ; \mathrm{M}=$ medium oregano diet; $\mathrm{H}=$ high oregano diet.

${ }^{2}$ Experiment 1 used Origanum vulgare ssp. vulgare with an essential oil (EO) content of $0.12 \%$ of DM. Diets contained $0,18,36$, and 53 g of oregano $\mathrm{DM} / \mathrm{kg}$ of dietary $\mathrm{DM}$ for $\mathrm{C}, \mathrm{L}, \mathrm{M}$, and $\mathrm{H}$, respectively.

${ }^{3} \mathrm{FCE}=$ feed conversion efficiency.

${ }^{4}$ Experiment 2 used Origanum vulgare ssp. hirtum with an EO content of $4.21 \%$ of DM. Diets contained 0, 7, 14, and $21 \mathrm{~g}$ of oregano DM/kg of dietary $\mathrm{DM}$ for $\mathrm{C}, \mathrm{L}, \mathrm{M}$, and $\mathrm{H}$, respectively.

methane production; however, diet had no effect $(P=$ 0.72; data not presented).

Carbon dioxide production and oxygen consumption responded cubically (both $P=0.01$ ) to increasing oregano doses (Table 6). Furthermore, the inclusion level of oregano did not affect hydrogen production.

\section{Milk Production, Composition, and FA Profile}

Experiment 1. Milk yield responded quadratically $(P=0.03)$ with increasing doses of low EO oregano; however, no effect was observed on ECM yield (Table 7). Feeding oregano also had no effect on milk composition or feed conversion efficiency. Feeding oregano with low levels of EO affected $\mathrm{C} 18: 3 \mathrm{n}-3$ in a quadratic way $(P=0.02)$ and a linear way (tendency, $P=0.06)$. The lowest values were obtained for the $\mathrm{C}$ diet, while the highest values were obtained for the $\mathrm{L}$ diet (Table 8). The concentration of $\mathrm{C} 18$ responded quadratically $(P$ $=0.05)$ to increasing doses of oregano. The inclusion level of oregano did not affect other FA, sum of MUFA, or total FA.

Experiment 2. Feeding increasing doses of oregano high in EO did not affect the milk-related variables (Table 7). Feeding increasing doses of high EO oregano affected the sum of PUFA $(P=0.03)$ and C18:2 cis6 cubically $(P=0.05)$, with the highest values being observed for the $\mathrm{H}$ diet and the lowest levels being observed for the $\mathrm{M}$ diet (Table 8). Feeding high EO oregano did not affect total FA or sum of C4 to C14, MUFA, and other FA.

\section{DISCUSSION}

\section{Oregano and Methane Production}

Oregano plant material (Tekippe et al., 2012) and EO extracted from oregano have been shown to decrease methane production in a dose-dependent way in vitro at high doses of $>300 \mathrm{mg} / \mathrm{L}$ (Benchaar and

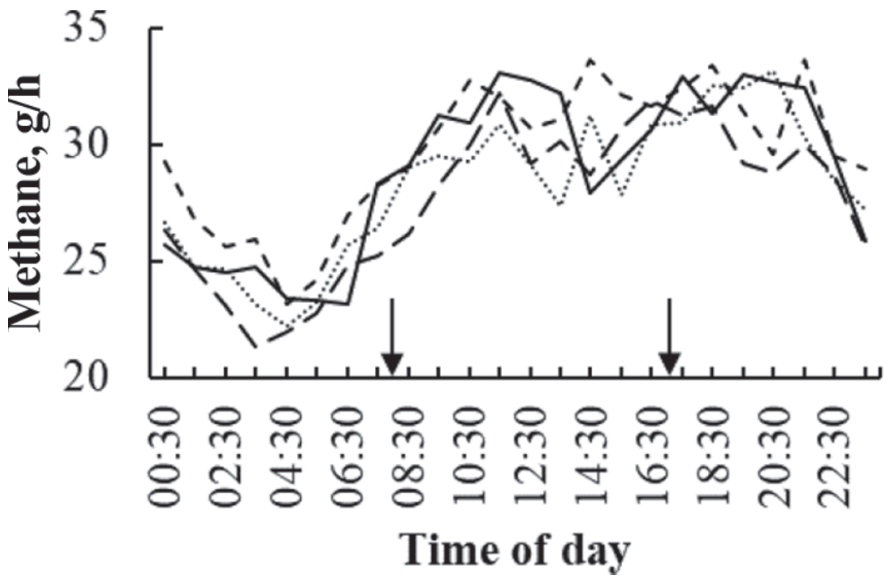

Figure 1. Least squares means for methane production per hour over a 24-h period for dairy cows fed a control diet (solid line, $0 \mathrm{~g}$ of oregano $\mathrm{DM} / \mathrm{kg}$ of dietary $\mathrm{DM}$ ) or a diet of oregano containing high levels of essential oils (low: long dashed line, $7 \mathrm{~g}$ of oregano $\mathrm{DM} / \mathrm{kg}$ of dietary DM; medium: short dashed line, $13.9 \mathrm{~g}$ of oregano $\mathrm{DM} / \mathrm{kg}$ of dietary DM; high: dotted line, $20.9 \mathrm{~g}$ of oregano $\mathrm{DM} / \mathrm{kg}$ of dietary $\mathrm{DM})$. Times of feeding are indicated with arrows. Each time point presents the average methane production for $30 \mathrm{~min}$ on either side of the time point (i.e., time point $0030 \mathrm{~h}$ presents the average methane production from 0000 to $0100 \mathrm{~h}$ ). 
Table 8. Fatty acids (FA) in milk (mg of FA/g of fat) of dairy cows fed different levels of dried oregano plant material

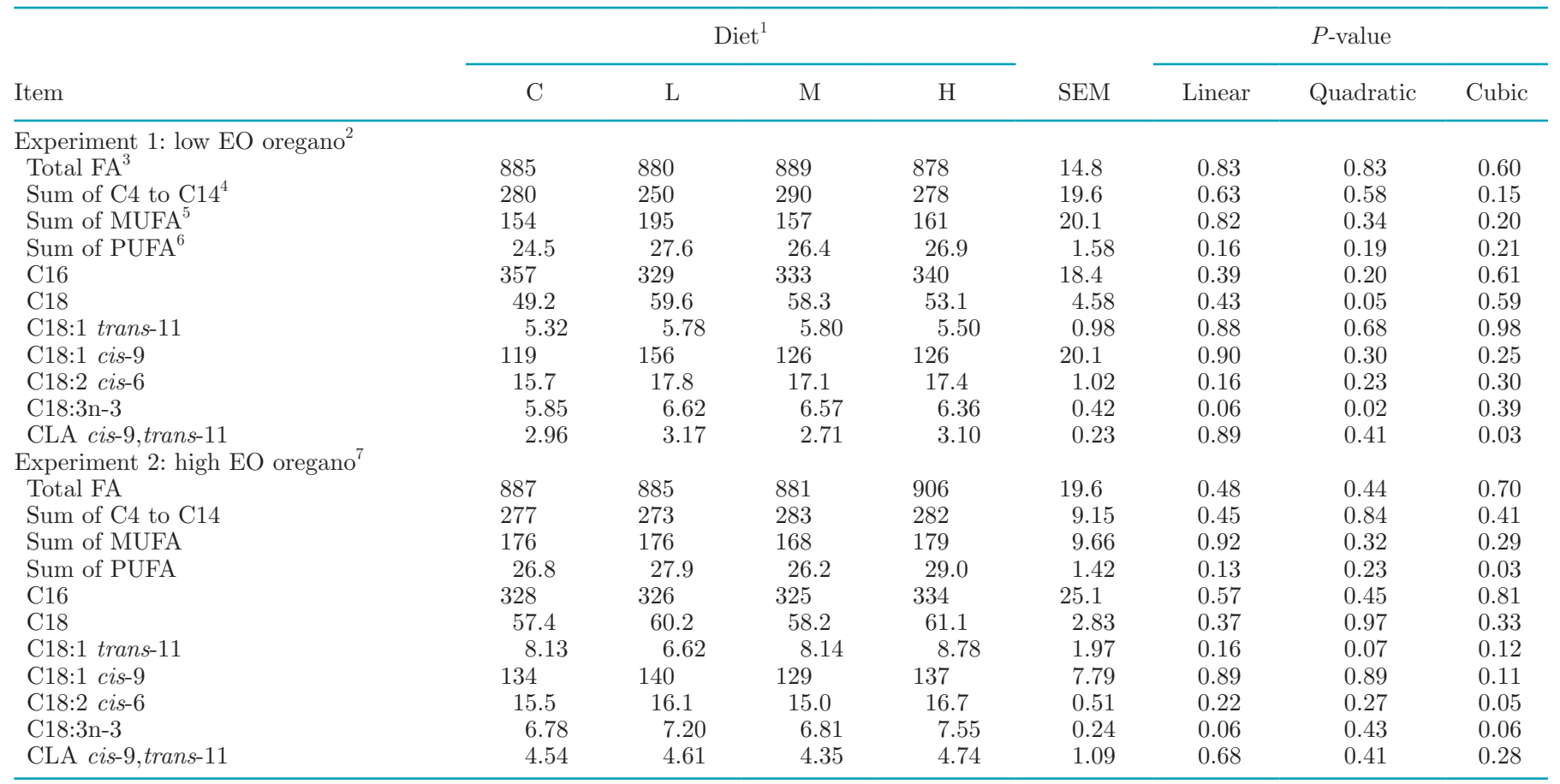

${ }^{1} \mathrm{C}=$ control diet; $\mathrm{L}=$ low oregano diet; $\mathrm{M}=$ medium oregano diet; $\mathrm{H}=$ high oregano diet.

${ }^{2}$ Experiment 1 used Origanum vulgare ssp. vulgare with an essential oil (EO) content of $0.12 \%$ of DM. Diets contained $0,18,36$, and 53 g of oregano $\mathrm{DM} / \mathrm{kg}$ of dietary $\mathrm{DM}$ for $\mathrm{C}, \mathrm{L}, \mathrm{M}$, and $\mathrm{H}$, respectively.

${ }^{3}$ Total FA is the sum of the following FA: C4, C6, C8, C10, C11, C12, C13, C14, C14:1, C15, C16, C16:1, C17, C17:1, C18, C18:1 trans-9, C18:1 trans-11, C18:1 cis-9, C18:2 cis-6, C20:1, C18:3n-3, CLA cis-9,trans-11, and C23.

${ }^{4} \mathrm{Sum}$ of $\mathrm{C} 4$ to $\mathrm{C} 14$ is the sum of the following FA: C4, C6, C8, C10, C11, C12, C13, and C14.

${ }^{5}$ Sum of MUFA is the sum of the following FA: C14:1, C16:1, C17:1, C18:1 trans-9, C18:1 trans-11, C18:1 cis-9, and C20:1.

${ }^{6} \mathrm{Sum}$ of PUFA is the sum of the following FA: C18:2 cis-6, C18:3n-3, and CLA cis-9,trans-11.

${ }^{7}$ Experiment 2 used Origanum vulgare ssp. hirtum with an EO content of $4.21 \%$ of DM. Diets contained 0, 7, 14, and $21 \mathrm{~g}$ of oregano DM/kg of dietary DM for $\mathrm{C}, \mathrm{L}, \mathrm{M}$, and $\mathrm{H}$, respectively.

Greathead, 2011) using cattle rumen liquid (Roy et al., 2014; Cobellis et al., 2015, 2016a; Chaudhary et al., 2016), which was suggested to be caused by a mode of action similar to that of ionophore antibiotics (Calsamiglia et al., 2007). However, our in vivo study with high EO Greek oregano showed that feeding oregano plant material as an EO source (Exp. 2) did not lower methane emissions from dairy cows when measured over 4 consecutive days. Thus, our hypothesis for Exp. 2 could not be confirmed. In Exp. 1, the Danish grown oregano subspecies $O$. vulgare ssp. vulgare with naturally low levels of EO also had no mitigating effect on methane emission, which agrees with our hypothesis; however, the low level of EO in oregano was unexpectedly low due to an unforeseen analytical error at the external laboratory ( $\mathrm{EO}$ concentration was expected to be $2.9 \%$ of DM), which was first discovered after the experiment was initiated. Essential oils are the main compounds in oregano that are responsible for mitigating methane production; however, other bioactive compounds (such as condensed tannins and flavonoids) might also inhibit methanogenesis. Tannins and flavonoids have both been associated with the inhibition of methanogenesis, as reviewed by Patra and Saxena (2010). We analyzed the tannin content of both oregano subspecies, which was below the detection limit of the analysis $(1.0 \mu \mathrm{g} /$ mg oregano DM). We did not analyze flavonoids in the present experiment; however, Greek oregano (O. vulgare ssp. hirtum) grown in Denmark has been reported to contain moderate levels of flavonoids $(4.8-12.4 \mathrm{mg} / \mathrm{g}$ DM; Grevsen et al., 2009) and that grown in Greece, high levels (47.9-71.2 mg/g DM; Gougoulias, 2009). Numbers for flavonoid concentrations for Danish grown oregano subspecies $O$. vulgare ssp. vulgare are lacking in literature, but data are available for flavonoids in O. vulgare ssp. vulgare from Germany $(5.1-7.4 \mathrm{mg} / \mathrm{g}$ DM; Röhricht and Mänicke, 2004). Neither subspecies of oregano used in our experiments appeared to contain other bioactive compounds at levels that could lower methane production in cows. It should be noted that 
the effectiveness of the oregano subspecies on gas production and fermentation has not been tested in vitro, which could have given valuable information on the consistency between the in vitro and in vivo results.

Our findings contrast with previous research reporting declines in methane production of $40 \%$ (grams of methane per hour; Tekippe et al., 2011) and 36\% (grams of methane per kilogram of DMI; Hristov et al., 2013) when $500 \mathrm{~g}$ of oregano leaf material (approximately 17.3 and $16.6 \mathrm{~g}$ of oregano $\mathrm{DM} / \mathrm{kg}$ of dietary DM for Tekippe et al., 2011 and Hristov et al., 2013) was fed to dairy cows. The contrasting outcomes might be attributed to differences in experimental procedures between our study and those of Tekippe et al. (2011) and Hristov et al. (2013), who also investigated the effectiveness of oregano material, rather than EO as such. First, the technique to measure methane emission and measurement period differed between studies; however, the technique as such might not explain the discrepancy in conclusions between our studies and Tekippe et al. (2011) and Hristov et al. (2013). Tekippe et al. (2011) and Hristov et al. (2013) used a modified sulfur hexafluoride $\left(\mathrm{SF}_{6}\right)$ tracer technique, for which gas samples of the rumen head space were collected as 2-hourly point samples for $8 \mathrm{~h}$ post-feeding. A large variability in methane production is reported for this modified $\mathrm{SF}_{6}$ technique (Tekippe et al., 2011) and the traditional $\mathrm{SF}_{6}$ technique, for which air is collected over $24 \mathrm{~h}$ near the nostrils (Grainger et al., 2007). Despite this large variability, Tekippe et al. (2011) observed a decline in hourly methane production $8 \mathrm{~h}$ post-feeding. In comparison, we used respiration chambers to measure gas exchange and DMI over 4 consecutive days with intervals of $12.5 \mathrm{~min}$ for methane concentrations and $1 \mathrm{~min}$ for feed intake. This approach made it possible to calculate methane production and DMI per hour. In Exp. 2, we found that hourly methane production and DMI were not affected by diet during $8 \mathrm{~h}$ postfeeding. Therefore, measuring for 8 and $24 \mathrm{~h}$ yielded consistent conclusions in the present study. However, Hristov et al. (2013) observed a linear decrease in daily DMI with increasing oregano doses; thus, if the linear decrease in DMI across treatments observed by Hristov et al. (2013) occurred during the 8-h gas measurement period, then their presented values for methane production on a daily basis and methane per kilogram of DMI might have been underestimated and biased, especially for the high oregano diet for which DMI was lowest. However, the authors did not specify the procedure for obtaining data for methane production per day and per kilogram of DMI from methane measurements made during $8 \mathrm{~h}$ and feed intake on a daily basis; therefore, our suggestion is speculative. Second, we mixed orega- no into TMR in the present studies, whereas Tekippe et al. (2011) and Hristov et al. (2013) offered oregano mixed with part of the TMR and fed on top of the remaining TMR. In the latter case, a large amount of EO entered the rumen in a short period; thus, a larger and acute effect on methane production and rumen fermentation could be expected post-feeding than would have occurred when oregano was mixed into TMR and entered the rumen gradually throughout the day, as in our experiment. Third, the EO concentrations and composition of oregano differed between studies. We fed oregano with $308 \mathrm{mg}$ of carvacrol $/ \mathrm{kg}$ of $\mathrm{DM}, 361$ $\mathrm{mg}$ of thymol $/ \mathrm{kg}$ of $\mathrm{DM}$, and $881 \mathrm{mg}$ of $\mathrm{EO} / \mathrm{kg}$ of $\mathrm{DM}$ for the $\mathrm{H}$ diet. The highest dose fed by Hristov et al. (2013) fed was $320 \mathrm{mg}$ of carvacrol/ $\mathrm{kg}$ of DM, $8 \mathrm{mg}$ of thymol $/ \mathrm{kg}$ of $\mathrm{DM}$, and $408 \mathrm{mg}$ of $\mathrm{EO} / \mathrm{kg}$ of $\mathrm{DM}$. Tekippe et al. (2011) applied EO at concentrations of $220 \mathrm{mg}$ of carvacrol $/ \mathrm{kg}$ of DM and $242 \mathrm{mg}$ of $\mathrm{EO} / \mathrm{kg}$ of DM. The high EO oregano in our study had similar carvacrol content to the oregano used by Hristov et al. (2013); however, the total EO concentration was double that in our study. Further, carvacrol and thymol are isomeric in their molecular structure and have been reported to have similar antimicrobial effects (Lambert et al., 2001; Xu et al., 2008). Hence, we expected to observe a methane mitigating effect, at least at the level observed by Hristov et al. (2013). In addition, feeding whole oregano plant material or only oregano leaves might not explain the discrepancies between studies, because the EO composition and concentration are more important for mitigation than the EO distribution between the stems and leaves.

In vivo evidence on the effectiveness of oregano EO, as such, is not consistent (Wang et al., 2009; Hristov et al., 2013; Lejonklev et al., 2016; Kolling et al., 2018). The effectiveness might depend on the dosage and mode of inclusion (plant material or EO). The doses of oregano in our study with high EO oregano could have been too low for providing methane mitigation compared with in vitro situations, in which methane mitigation has been observed (Benchaar and Greathead, 2011). If EO should be a methane mitigation tool, then further studies are required on dosage and the mode of inclusion (EO or plant material), taking into account the palatability of the diet and feed costs. Other aspects to consider are that antimicrobial effects might be reduced due to loss during mastication and eructation (Welch and Pederson, 1981; White et al., 1982), degradation by rumen microbes (Malecky et al., 2012), and absorption into the blood from the rumen (Malecky et al., 2009). Moreover, rumen microbes might be able to adapt to EO, limiting their use in the long term (Benchaar and Greathead, 2011). 


\section{Apparent Nutrient Digestibility} and Rumen Fermentation

The lack of effect of high EO oregano on methane production documented in our study was supported by minimal effects on rumen fermentation and apparent nutrient digestibility, as opposed to our hypothesis. Apparent nutrient digestibility in digestive tract sections (rumen, small intestine, and large intestine) was not affected by feeding oregano in the 2 experiments, but the total-tract apparent digestibility of DM, OM, and NDF was affected in both experiments. This observation suggests that the fecal samples were more representative than the digesta samples as reflected in the smaller standard error for total-tract digestibility than for digestive tract sections. In Exp. 2, the apparent total-tract digestibility of NDF was between 1.7 and $4.1 \%$ units less for oregano diets relative to $\mathrm{C}$, which agrees with our hypothesis. Hristov et al. (2013) also reported lower apparent total-tract digestibility of NDF of about $2 \%$ units when feeding oregano plant material, irrespective of dose, but not for DM and OM. Kolling et al. (2018) documented no effect of oregano extract on the apparent total-tract digestibility of DM, CP (tendency), and NDF. Thus, the decreased apparent total-tract digestibility of NDF, and presumably DM and $\mathrm{OM}$, in our study might be explained by the fact that we replaced grass/clover silage with lower digestible oregano, rather than the effects of EO. All diets used in the 2 experiments had similar NDF content, but might have had different iNDF content (iNDF was not analyzed in TMR) because oregano has a greater iNDF content than grass/clover silage. This phenomenon might explain the linear decrease in apparent rumen NDF digestibility with increasing oregano dose in Exp. 1. Furthermore, the decline in total-tract OM digestibility was supported by the decline in digestible OM content measured in vitro.

The apparent total-tract digestibility of CP declined in Exp. 2, as well as in Exp. 1 for the oregano diets that had increased dietary content of oregano. Hristov et al. (2013) and Kolling et al. (2018) both reported a tendency for lower apparent total-tract digestibility of CP in the control diet compared with diets with oregano plant material or oregano extract, irrespective of dose. Again, replacing grass/clover silage with oregano might have contributed to the lowered apparent total-tract digestibility of $\mathrm{CP}$ in our study. However, it is possible that EO affect protein digestibility, because the effects were more pronounced in Exp. 2 with high EO oregano, which was also documented with oregano EO extract (Kolling et al., 2018). The lowered apparent CP digest- ibility in the small and large intestine observed in Exp. 1 was not observed in Exp. 2. This difference might be attributed to the presence of fiber-bound low-digestible $\mathrm{CP}$ in oregano; however, this suggestion is speculative.

Apparent digestibility coefficients of NDF in the small intestine were negative, which is unrealistic, but is a common observation (Brask et al., 2013; Olijhoek et al., 2016). A negative digestibility value represents a net gain in NDF over the small intestine, which has also been observed from duodenum to feces (Poore et al., 1993; calculated based on presented data). Similar negative values for NDF digestibility in the small intestine were found for chromic oxide and iNDF as markers (Brask et al., 2013); therefore, negative values could perhaps be attributed to taking representative samples from intestinal cannulas with respect to the fiber fraction.

Rumen fermentation was slightly affected in both experiments. Our results support those of Hristov et al. (2013), who did not observe changes in total VFA concentration, A:P ratio, or molar proportions of acetate and propionate. Furthermore, unaltered VFA molar proportions were reported previously (Wang et al., 2009; Tekippe et al., 2011; Kolling et al., 2018; Paraskevakis, 2018). The main effect of feeding low EO oregano on rumen fermentation was a decline in microbial CP synthesis in Exp. 1. This decline was mainly driven by the $\mathrm{H}$ diet, with a similar pattern being documented in both experiments, although it was not significant when feeding cows high EO oregano (Exp. 2), supporting the work of Hristov et al. (2013). Essential oils are not assumed to be responsible for the decline because they were present at low levels in the oregano used in Exp. 1. Moreover, the decline did not seem to be related to an imbalance between nitrogen and energy availability in the rumen because the microbial efficiency was not affected by feeding oregano in either experiment. In addition, nitrogen intake and dietary nitrogen content were similar between diets within experiments. Furthermore, the ammonia concentration in rumen liquid was not affected by feeding increasing doses of oregano (both experiments). In short, the observed decline in microbial CP synthesis (Exp. 1) could not be explained.

From the analysis for rumen bacterial community structure (Exp. 2), we found no differences in the major and minor bacterial community members (results not presented). Previously, Hristov et al. (2013) found that the addition of oregano lowered the proportion of fibrolytic bacteria (e.g., Ruminococcus flavefaciens) out of the total sequences, whereas the archaeal community of the rumen was not affected in the studies by Tekippe et al. (2011) and Hristov et al. (2013). 


\section{DMI and Milk-Related Variables}

Dry matter intake of the cows in Exp. 1 was higher during gas measurements than during digesta collection; however, this pattern was not observed in Exp. 2. A higher feed intake in respiration chambers than during digesta collection has also occurred in earlier experiments with the same experimental design and procedures at our institute and seems to occur randomly. Dry matter intake was not affected by feeding low or high EO oregano, indicating that the doses of oregano fed to cows did not affect diet palatability. In agreement, DMI was not affected when feeding oregano material (Tekippe et al., 2011) or oregano EO (Wang et al., 2009; Lejonklev et al., 2016). In contrast, Hristov et al. (2013) observed a linear decrease in DMI with increasing oregano doses. Similar to previous studies (Tekippe et al., 2011; Hristov et al., 2013; Lejonklev et al., 2016; Kolling et al., 2018), milk yield was not affected in the 2 experiments of our study. Milk composition was also unaffected in our study and in that of Hristov et al. (2013), whereas other studies reported either increased or decreased fat and protein content (Tekippe et al., 2011; Lejonklev et al., 2016; Kolling et al., 2018). Feed conversion efficiency was similar between diets of our experiments. Thus, oregano with either low or high levels of EO does not seem to affect feed conversion efficiency, despite the literature reporting the modes of action for carvacrol and thymol as being similar to ionophore antibiotics (Calsamiglia et al., 2007). In contrast, improved feed efficiency has been previously reported, with $3.5 \%$ FCM per kilogram of DMI (Tekippe et al., 2011) and kilogram of milk per kilogram of DMI (Hristov et al., 2013). However, the measurement period and the number of cows and observations were relatively low in our study to obtain accurate estimates of feed efficiency for the different diets.

Finally, milk composition and FA profile, as opposed to our hypothesis, were not affected by the inclusion level of oregano with either high or low EO content (except for C18:3n-3 in Exp. 1), supporting Hristov et al. (2013), who found that oregano had no effect on milk composition or FA profile. In addition, raw milk was tested by a professional sensory panel of a dairy company, with generally no off-taste in the milk being identified (data not presented). Likewise, Lacerda et al. (2014) reported that feeding dried oregano material did not affect the sensory attributes of milk from dairy cows. Altered sensory aspects have been reported with the inclusion of oregano EO in dairy cattle diets; however, this change was not considered to be unfavorable (Lejonklev et al., 2016).

\section{CONCLUSIONS}

Dried oregano plant material with low or high levels of EO fed in different doses did not lower methane emission from dairy cows measured over 4 consecutive days. This finding was supported by the fact that we observed no substantial effects on rumen fermentation, apparent nutrient digestibility in different sections of the digestive tract, or milk FA composition. Observed effects on nutrient digestibility might be caused by replacing grass/clover silage with low digestible oregano, rather than effects of EO per se. Overall, the conclusion regarding methane production is in contrast with literature and requires further study.

\section{ACKNOWLEDGMENTS}

Torkild N. Jakobsen and Amin T. Aljundi (Aarhus University Foulum, Tjele, Denmark), barn staff, and laboratory technicians are gratefully acknowledged for providing skillful assistance during the experiments and handling of samples. This study was funded by the Danish Milk Levy Fund (Aarhus, Denmark), Green Development and Demonstration Program (GUDP, Copenhagen, Denmark), and Aarhus University (Aarhus, Denmark).

\section{REFERENCES}

AOAC International. 2000. AOAC Official Methods of Analysis. 17th ed. AOAC International, Washington, DC.

Benchaar, C., and H. Greathead. 2011. Essential oils and opportunities to mitigate enteric methane emissions from ruminants. Anim. Feed Sci. Technol. 166-167:338-355.

Bolyen, E., J. R. Rideout, M. R. Dillon, N. A. Bokulich, C. Abnet, G. A. Al-Ghalith, H. Alexander, E. J. Alm, M. Arumugam, F. Asnicar, Y. Bai, J. E. Bisanz, K. Bittinger, A. Brejnrod, C. J. Brislawn, C. T. Brown, B. J. Callahan, A. M. Caraballo-Rodriguez, J. Chase, E. Cope, R. Da Silva, P. C. Dorrestein, G. M. Douglas, D. M. Durall, C. Duvallet, C. F. Edwardson, M. Ernst, M. Estaki, J. Fouquier, J. M. Gauglitz, D. L. Gibson, A. Gonzalez, K. Gorlick, J. Guo, B. Hillmann, S. Holmes, H. Holste, C. Huttenhower, G. Huttley, S. Janssen, A. K. Jarmusch, L. Jiang, B. Kaehler, K. B. Kang, C. R. Keefe, P. Keim, S. T. Kelley, D. Knights, I. Koester, T. Kosciolek, J. Kreps, M. G. I. Langille, J. Lee, R. Ley, Y. Liu, E. Loftfield, C. Lozupone, M. Maher, C. Marotz, B. D. Martin, D. McDonald, L. J. McIver, A. V. Melnik, J. L. Metcalf, S. C. Morgan, J. T. Morton, A. T. Naimey, J. A. Navas-Molina, L. F. Nothias, S. B. Orchanian, T. Pearson, S. L. Peoples, D. Petras, M. L. Preuss, E. Pruesse, L. B. Rasmussen, A. Rivers, M. S. I. I. Robeson, P. Rosenthal, N. Segata, M. Shaffer, A. Shiffer, R. Sinha, S. J. Song, J. R. Spear, A. D. Swafford, L. R. Thompson, P. J. Torres, P. Trinh, A. Tripathi, P. J. Turnbaugh, S. Ul-Hasan, J. J. J. van der Hooft, F. Vargas, Y. Vázquez-Baeza, E. Vogtmann, M. von Hippel, W. Walters, Y. Wan, M. Wang, J. Warren, K. C. Weber, C. H. D. Williamson, A. D. Willis, Z. Z. Xu, J. R. Zaneveld, Y. Zhang, Q. Zhu, R. Knight, and J. G. Caporaso. 2018. QIIME 2: Reproducible, interactive, scalable, and extensible microbiome data science. PeerJ Preprints 6:e27295v2. https://doi .org/10.7287/peerj.preprints.27295v2. 
Bosabalidis, A. M. 2002. Structural features of Origanum sp. Pages 1164 in Medicinal and Aromatic Plants-Industrial Profiles, Oregano. The Genera Origanum and Lippia. Vol. 25. S. E. Kintzios, ed. Taylor \& Francis, London, UK, and New York, NY.

Brask, M., P. Lund, A. L. F. Hellwing, M. Poulsen, and M. R. Weisbjerg. 2013. Enteric methane production, digestibility and rumen fermentation in dairy cows fed different forages with and without rapeseed fat supplementation. Anim. Feed Sci. Technol. 184:67-79.

Brask, M., M. R. Weisbjerg, A. L. F. Hellwing, A. Bannink, and P. Lund. 2015. Methane production and diurnal variation measured in dairy cows and predicted from fermentation pattern and nutrient or carbon flow. Animal 9:1795-1806.

Callahan, B. J., P. J. McMurdie, M. J. Rosen, A. W. Han, A. J. A Johnson, and S. P. Holmes. 2016. DADA2: High-resolution sample inference from Illumina amplicon data. Nat. Methods 13:581-583.

Calsamiglia, S., M. Busquet, P. W. Cardozo, L. Castillejos, and A. Ferret. 2007. Invited review: Essential oils as modifiers of rumen microbial fermentation. J. Dairy Sci. 90:2580-2595.

Canibe, N., O. Hojberg, J. H. Badsberg, and B. B. Jensen. 2007. Effect of feeding fermented liquid feed and fermented grain on gastrointestinal ecology and growth performance in piglets. J. Anim. Sci. 85:2959-2971.

Chaudhary, P. P., N. Goel, G. Baker, J. Saxena, N. Singh, I. Chaturvedi, A. Sharma, and S. K. Sirohi. 2016. Influence of essential oils supplementation on rumen fermentation profile and ruminal microbial population in vitro. J. Sci. 1:25-34.

Cobellis, G., A. Petrozzi, C. Forte, G. Acuti, M. Orrù, M. C. Marcotullio, A. Aquino, A. Nicolini, V. Mazza, and M. Trabalza-Marinucci. 2015. Evaluation of the effects of mitigation on methane and ammonia production by using Origanum vulgare L. and Rosmarinus officinalis L. essential oils on in vitro rumen fermentation systems. Sustainability $7: 12856-12869$.

Cobellis, G., M. Trabalza-Marinucci, M. C. Marcotullio, and Z. Yu. 2016a. Evaluation of different essential oils in modulating methane and ammonia production, rumen fermentation, and rumen bacteria in vitro. Anim. Feed Sci. Technol. 215:25-36.

Cobellis, G., M. Trabalza-Marinucci, and Z. Yu. 2016b. Critical evaluation of essential oils as rumen modifiers in ruminant nutrition: A review. Sci. Total Environ. 545-546:556-568.

Gougoulias, N. 2009. Study on polyphenols content and antioxidative activity of oregano (Origanum vulgare L.) of different origin. Oxid. Commun. 32:917-923.

Grainger, C., T. Clarke, S. M. McGinn, M. J. Auldist, K. A. Beauchemin, M. C. Hannah, G. C. Waghorn, H. Clark, and R. J. Eckard. 2007. Methane emissions from dairy cows measured using the sulfur hexafluoride (SF6) tracer and chamber techniques. J. Dairy Sci. 90:2755-2766.

Grevsen, K., X. C. Fretté, and L. P. Christensen. 2009. Content and composition of volatile terpenes, flavonoids and phenolic acids in Greek oregano (Origanum vulgare L. ssp. hirtum) at different development stages during cultivation in cool temperate climate. Eur. J. Hortic. Sci. 74:193-203.

Hansen, B. 1989. Determination of nitrogen as elementary-N, an alternative to Kjeldahl. Acta Agric. Scand. A Anim. Sci. 39:113-118.

Hellwing, A. L. F., P. Lund, M. R. Weisbjerg, M. Brask, and T. Hvelplund. 2012. Technical note: Test of a low-cost and animal-friendly system for measuring methane emissions from dairy cows. J. Dairy Sci. 95:6077-6085.

Hristov, A. N., C. Lee, T. T. Cassidy, K. Heyler, J. A. Tekippe, G. A. Varga, B. Corl, and R. C. Brandt. 2013. Effect of Origanum vulgare L. leaves on rumen fermentation, production, and milk fatty acid composition in lactating dairy cows. J. Dairy Sci. 96:1189-1202.

Jensen, M. T., K. P. Cox, and B. B. Jensen. 1995. Microbial production of skatole in the hind gut of pigs given different diets and its relation to skatole deposition in backfat. Anim. Sci. 61:293-304.

Klindworth, A., E. Pruesse, T. Schweer, J. Peplies, C. Quast, M. Horn, and F. O. Glöckner. 2013. Evaluation of general $16 \mathrm{~S}$ ribosomal RNA gene PCR primers for classical and next-generation sequencing-based diversity studies. Nucleic Acids Res. 41:e1.

Knapp, J. R., G. L. Laur, P. A. Vadas, W. P. Weiss, and J. M. Tricarico. 2014. Invited review: Enteric methane in dairy cattle pro- duction: Quantifying the opportunities and impact of reducing emissions. J. Dairy Sci. 97:3231-3261.

Kolling, G. J., S. C. B. Stivanin, A. M. Gabbi, F. S. Machado, A. L. Ferreira, M. M. Campos, T. R. Tomich, C. S. Cunha, S. W. Dill, L. G. R. Pereira, and V. Fischer. 2018. Performance and methane emissions in dairy cows fed oregano and green tea extracts as feed additives. J. Dairy Sci. 101:4221-4234.

Krämer, M., M. R. Weisbjerg, P. Lund, C. S. Jensen, and M. G. Pedersen. 2012. Estimation of indigestible NDF in forages and concentrates from cell wall composition. Anim. Feed Sci. Technol. 177:40-51.

Kristensen, N. B., A. Storm, B. M. L. Raun, B. A. Røjen, and D. L. Harmon. 2007. Metabolism of silage alcohols in lactating dairy cows. J. Dairy Sci. 90:1364-1377.

Lacerda, E. C. Q., L. C. Bauer, J. S. Oliveira, F. F. Silva, S. A. Carvalho, M. S. Macedo, N. E. de Souza, and J. I. Simionato. 2014. Short communication: Effect of the dietary inclusion of dried oregano (Origanum vulgare L.) on the characteristics of milk from Holstein $\times$ Zebu cows. Anim. Feed Sci. Technol. 192:101-105.

Lambert, R. J. W., P. N. Skandamis, P. J. Coote, and G.-J. E. Nychas. 2001. A study of the minimum inhibitory concentration and mode of action of oregano essential oil, thymol and carvacrol. J. Appl. Microbiol. 91:453-462.

Larsen, M. K., U. Kidmose, T. Kristensen, P. Beaumont, and G. Mortensen. 2013. Chemical composition and sensory quality of bovine milk as affected by type of forage and proportion of concentrate in the feed ration. J. Sci. Food Agric. 93:93-99.

Lejonklev, J., U. Kidmose, S. Jensen, M. A. Petersen, A. L. F. Hellwing, G. Mortensen, M. R. Weisbjerg, and M. K. Larsen. 2016. Effect of oregano and caraway essential oils on the production and flavor of cow milk. J. Dairy Sci. 99:7898-7903.

Lukas, B., C. Schmiderer, and J. Novak. 2015. Essential oil diversity of European Origanum vulgare L. (Lamiaceae). Phytochemistry 119:32-40.

Lund, P., M. R. Weisbjerg, and T. Hvelplund. 2003. Effect of forage type and supplementation on microbial synthesis and efficiency in the rumen of dairy cows. Pages $627-630$ in EAAP Publication 109: Progress in Research on Energy and Protein Metabolism. Wageningen Academic Publishers, Wageningen, the Netherlands.

Malecky, M., H. Albarello, and L. P. Broudiscou. 2012. Degradation of terpenes and terpenoids from Mediterranean rangelands by mixed rumen bacteria in vitro. Animal 6:612-616.

Malecky, M., L. P. Broudiscou, and P. Schmidely. 2009. Effects of two levels of monoterpene blend on rumen fermentation, terpene and nutrient flows in the duodenum and milk production in dairy goats. Anim. Feed Sci. Technol. 154:24-35.

Mertens, D. R. 2002. Gravimetric determination of amylase-treated neutral detergent fiber in feeds with refluxing in beakers or crucibles: Collaborative study. J. AOAC Int. 85:1217-1240.

Myers, W. D., P. A. Ludden, V. Nayigihugu, and B. W. Hess. 2004. Technical note: A procedure for the preparation and quantitative analysis of samples for titanium dioxide. J. Anim. Sci. 82:179-183.

Olijhoek, D. W., A. L. F. Hellwing, M. Brask, M. R. Weisbjerg, O. Højberg, M. K. Larsen, J. Dijkstra, E. J. Erlandsen, and P. Lund. 2016. Effect of dietary nitrate level on enteric methane production, hydrogen emission, rumen fermentation, and nutrient digestibility in dairy cows. J. Dairy Sci. 99:6191-6205.

Owens, F. N., and C. F. Hanson. 1992. External and internal markers for appraising site and extent of digestion in ruminants. J. Dairy Sci. 75:2605-2617.

Paraskevakis, N. 2018. Effects of dietary Greek oregano (Origanum vulgare ssp. hirtum) supplementation on rumen fermentation, enzyme profile and microbial communities in goats. J. Anim. Physiol. Anim. Nutr. (Berl.) 102:701-705.

Patra, A. K., and J. Saxena. 2010. A new perspective on the use of plant secondary metabolites to inhibit methanogenesis in the rumen. Phytochemistry 71:1198-1222.

Poore, M. H., J. A. Moore, T. P. Eck, R. S. Swingle, and C. B. Theurer. 1993. Effect of fiber source and ruminal starch degradability on site and extent of digestion in dairy cows. J. Dairy Sci $76: 2244-2253$. 
Röhricht, C., and S. Mänicke. 2004. Ertrag, Inhaltsstoffe und antioxidative sowie fungizide Wirkung verschiedener Herkünfte von Dost (Origanum vulgare L.). Z. Arznei Gewurzpflanzen 9:158-166. [In German]

Roy, D., S. K. Tomar, S. K. Sirohi, V. Kumar, and M. Kumar. 2014. Efficacy of different essential oils in modulating rumen fermentation in vitro using buffalo rumen liquor. Vet. World 7:213-218.

Schürch, A. F., L. E. Lloyd, and E. W. Crampton. 1950. The use of chromic oxide as an index for determining the digestibility of a diet. J. Nutr. 41:629-636.

Sjaunja, L. O., L. Baevre, L. Junkkarinen, J. Pedersen, and J. Setala. 1991. A Nordic proposal for an energy corrected milk (ECM) formula. Pages 156-157 in EAAP publication 50: Performance Recording of Animals: State of the Art 1990. Performance Centre for Agricultural Publishing and Documentation (PUDOC), Wageningen, the Netherlands.

Stoldt, W. 1952. Vorschlag zur vereinheitlichung der fettbestimmung in lebensmitteln. Fette und Seifen 54:206-207. [In German]

Tekippe, J. A., A. N. Hristov, K. S. Heyler, T. W. Cassidy, V. D. Zheljazkov, J. F. S. Ferreira, S. K. Karnati, and G. A. Varga. 2011. Rumen fermentation and production effects of Origanum vulgare L. leaves in lactating dairy cows. J. Dairy Sci. 94:5065-5079.

Tekippe, J. A., A. N. Hristov, K. S. Heyler, V. D. Zheljazkov, J. F. S. Ferreira, C. L. Cantrell, and G. A. Varga. 2012. Effects of plants and essential oils on ruminal in vitro batch culture methane production and fermentation. Can. J. Anim. Sci. 92:395-408.

Thode, S. 1997. Bestemmelse af puriner i vom- og duodenummateriale hos kvaeg. Intern Rapport nr. 93. Danish Institute of Agricultural Sciences, Foulum, Denmark. [In Danish]

Tilley, J. M. A., and R. A. Terry. 1963. A two-stage technique for in vitro digestion of forage crops. Grass Forage Sci. 18:104-111.
Veres, K., E. Varga, Á. Dobos, Zs. Hajdú, I. Máthé, É. Németh, and K. Szabó. 2003. Investigation of the composition and stability of the essential oils of Origanum vulgare ssp. vulgare $\mathrm{L}$. and $O$. vulgare ssp. hirtum (Link) Ietswaart. Chromatographia 57:95-98.

Vokou, D., S. Kokkini, and J.-M. Bessiere. 1993. Geographic variation of Greek oregano (Origanum vulgare ssp. hirtum) essential oils. Biochem. Syst. Ecol. 21:287-295.

Volden, H. 2011. NorFor-The Nordic Feed Evaluation System. EAAP publication no. 130. Wageningen Academic Publishers, Wageningen, the Netherlands.

Volden, H., and N. I. Nielsen. 2011. Energy and metabolizable protein supply. Pages 81-84 in NorFor-The Nordic Feed Evaluation System. EAAP publication no. 130. H. Volden, ed. Wageningen Academic Publishers, Wageningen, the Netherlands.

Wang, C. J., S. P. Wang, and H. Zhou. 2009. Influences of flavomycin, ropadiar, and saponin on nutrient digestibility, rumen fermentation, and methane emission from sheep. Anim. Feed Sci. Technol. 148:157-166.

Welch, B. L., and J. C. Pederson. 1981. In vitro digestibility among accessions of big sagebrush by wild mule deer and its relationship to monoterpenoid content. J. Range Manage. 34:497-500.

White, S. M., B. L. Welch, and J. T. Flinders. 1982. Monoterpenoid content of pygmy rabbit stomach ingesta. J. Range Manage. 35:107-109.

Xu, J., F. Zhou, B.-P. Ji, R.-S. Pei, and N. Xu. 2008. The antibacterial mechanism of carvacrol and thymol against Escherichia coli. Lett. Appl. Microbiol. 47:174-179.

Zinn, R. A., and F. N. Owens. 1986. A rapid procedure for purine measurement and its use for estimating net ruminal protein synthesis. Can. J. Anim. Sci. 66:157-166. 